University of Wollongong

Research Online

Faculty of Engineering and Information

Faculty of Engineering and Information

Sciences - Papers: Part A

Sciences

$1-1-2015$

Degradation of a broad spectrum of trace organic contaminants by an enzymatic membrane reactor: complementary role of membrane retention and enzymatic degradation

\author{
Luong N. Nguyen \\ University of Wollongong, luong@uow.edu.au \\ Faisal I. Hai \\ University of Wollongong, faisal@uow.edu.au \\ William E. Price \\ University of Wollongong,wprice@uow.edu.au \\ Jinguo Kang \\ University of Wollongong, jkang@uow.edu.au \\ Frederic D.L Leusch \\ Griffith University
}

See next page for additional authors

Follow this and additional works at: https://ro.uow.edu.au/eispapers

Part of the Engineering Commons, and the Science and Technology Studies Commons

Research Online is the open access institutional repository for the University of Wollongong. For further information contact the UOW Library: research-pubs@uow.edu.au 


\title{
Degradation of a broad spectrum of trace organic contaminants by an enzymatic membrane reactor: complementary role of membrane retention and enzymatic degradation
}

\begin{abstract}
Laccase-catalysed degradation of 30 trace organic contaminants (TrOCs) with diverse chemical structure was investigated in an enzymatic membrane reactor (EMR) equipped with an ultrafiltration membrane. Compared to the results from batch incubation tests, the EMR could facilitate degradation of some phenolic and a number of non-phenolic TrOCs. Laccase, which was completely retained by the membrane, formed a dynamic gel layer on the membrane surface onto which TrOCs were adsorbed. EMR investigations with active and heat-inactivated laccase confirmed that the TrOCs retained by the active laccase gel layer were eventually degraded. Redox-mediator addition to the EMR significantly extended the spectrum of efficiently degraded TrOCs, but a limited improvement was observed in batch tests. The results demonstrate the important role of TrOC retention by the enzyme gel layer dynamically formed on the membrane in achieving improved degradation of TrOCs by the mediator-assisted laccase system. Despite following the same hydrogen atom transfer pathway, the mediators tested (syringaldehyde and 1-hydroxybenzotriazole) exhibited TrOC-specific degradation improvement capacity.

Disciplines

Engineering | Science and Technology Studies

\section{Publication Details}

Nguyen, L. N., Hai, F. I., Price, W. E., Kang, J., Leusch, F. D.L ., Roddick, F., van de Merwe, J. P., Magram, S. F. \& Nghiem, L. D. (2015). Degradation of a broad spectrum of trace organic contaminants by an enzymatic membrane reactor: complementary role of membrane retention and enzymatic degradation. International Biodeterioration and Biodegradation, 99 115-122.

\section{Authors}

Luong N. Nguyen, Faisal I. Hai, William E. Price, Jinguo Kang, Frederic D.L Leusch, Felicity Roddick, Jason P. van de Merwe, Saleh F. Magram, and Long D. Nghiem
\end{abstract}


Degradation of a broad spectrum of trace organic contaminants by an enzymatic membrane reactor: Complementary role of membrane retention and enzymatic degradation

\section{International Biodeterioration \& Biodegradation Vol 99, 20155 pp: 115-122} http://www.sciencedirect.com/science/article/pii/S0964830514003631

Luong N. Nguyen ${ }^{a}$, Faisal I. Hai ${ }^{a *}$, William E. Price ${ }^{b}$, Jinguo Kang ${ }^{b}$, Frederic D.L. Leusch ${ }^{c}$, Felicity Roddick ${ }^{\mathrm{d}}$, Jason P. van de Merwe ${ }^{\mathrm{c}}$, Saleh F. Magram ${ }^{\mathrm{e}}$, Long D. Nghiem ${ }^{\mathrm{a}}$

${ }^{a}$ Strategic Water Infrastructure Lab, School of Civil, Mining and Environmental Engineering, University of Wollongong, Wollongong, NSW 2522, Australia.

${ }^{\mathrm{b}}$ Strategic Water Infrastructure Lab, School of Chemistry, University of Wollongong, Wollongong, NSW 2522, Australia.

${ }^{\mathrm{c}}$ Smart Water Research Centre, Griffith University, QLD 4222, Australia

${ }^{\mathrm{d}}$ School of Civil, Environmental and Chemical Engineering, RMIT University, Melbourne, Victoria 3001, Australia

${ }^{\mathrm{e}}$ Department of Civil Engineering, King Abdul Aziz University, Jeddah 21589, Saudi Arabia

*Corresponding author: Faisal I. Hai, E-mail: faisal@uow.edu.au, Ph: + 61242213054 


\section{Research Highlights}

- Laccase degradation of 30 diverse TrOCs in an EMR was investigated

- TrOC retention by gel layer on membrane facilitated their enzymatic degradation

- Mediator addition led to higher ORP but little increase in batch TrOC degradation

- Mediator addition broadened the spectrum of efficiently degraded TrOCs in the EMR

- Mediator 1-hydroxybenzotriazole was more effective for removing non-phenolic TrOCs 


\begin{abstract}
:
Laccase-catalysed degradation of 30 trace organic contaminants (TrOCs) with diverse chemical structure was investigated in an enzymatic membrane reactor (EMR) equipped with an ultrafiltration membrane. Compared to the results from batch incubation tests, the EMR could facilitate degradation of some phenolic and a number of non-phenolic TrOCs. Laccase, which was completely retained by the membrane, formed a dynamic gel layer on the membrane surface onto which TrOCs were adsorbed. EMR investigations with active and heat-inactivated laccase confirmed that the TrOCs retained by the active laccase gel layer were eventually degraded. Redox-mediator addition to the EMR significantly extended the spectrum of efficiently degraded TrOCs, but a limited improvement was observed in batch tests. The results demonstrate the important role of TrOC retention by the enzyme gel layer dynamically formed on the membrane in achieving improved degradation of TrOCs by the mediator-assisted laccase system. Despite following the same hydrogen atom transfer pathway, the mediators tested (syringaldehyde and 1-hydroxybenzotriazole) exhibited TrOCspecific degradation improvement capacity.
\end{abstract}

Keywords: Enzymatic membrane reactor (EMR); trace organic contaminants (TrOCs); laccase; Redox-mediator. 


\section{Introduction}

Trace organic contaminants (TrOCs) are ubiquitous in wastewater, and water sources polluted by wastewater. These TrOCs include, but are not limited to, pharmaceutically active compounds, industrial chemicals, pesticides, and natural and artificial hormones. Some TrOCs have been observed to bring about detrimental physiological changes in aquatic fauna. Under prolonged exposure, TrOCs may also affect human health (Schwarzenbach et al., 2006). Conventional wastewater treatment plants do not effectively remove TrOCs (Luo et al., 2014). Thus for both safe discharge into the environment and wastewater reuse it is important to develop effective wastewater treatment processes.

Enzymatic degradation of wastewater-borne resistant pollutants has gained much attention in recent years. Compared to conventional chemical oxidation, enzymatic degradation can be achieved under milder conditions, while realizing higher rates and reaction specificity. Laccases (EC 1.10.3.2) are copper-containing oxidoreductase enzymes that can use atmospheric oxygen as the terminal oxidant. Laccase has been used in various industrial biotechnology processes such as denim bleaching and pulp delignification. It has also been reported to efficiently degrade resistant compounds including aromatic hydrocarbons and dyes (Modin et al., 2014). Recent studies demonstrate that laccase can efficiently degrade a broad spectrum of TrOCs that are hardly degradable by conventional biological processes (Cabana et al., 2007; Yang et al., 2013). Notably, most of the available studies on enzymatic degradation of resistant compounds in general and $\mathrm{TrOC}$ in particular have been conducted in small scale and batch mode.

Enzymatic TrOC degradation may depend on various factors such as chemical structure of the TrOCs, chemistry of the reaction media (i.e., $\mathrm{pH}$, temperature and ionic strength), and the characteristics of the enzyme applied (Yang et al., 2013). Laccase can efficiently degrade compounds with phenolic moeity including diphenols, methoxy-substituted monophenols as well as aromatic/aliphatic amines. For compounds which possess higher redox potential than laccase, or are too large to gain access to the active sites of the enzyme, addition of redoxmediators may facilitate their oxidation. Mediators are low-molecular weight substrates of laccase which can act as "electron carrier" between the enzyme and the target pollutant. However, the efficiency of a laccase - mediator system depends largely on mediator type and the molecular structure of TrOCs (Yang et al., 2013). 
Enzyme-washout with treated effluent is a critical problem encountered during their application in continuous systems such as wastewater treatment plants. By using a membrane with an appropriate pore size relative to the enzyme molecule, an enzymatic membrane reactor (EMR) can prevent enzyme washout. This approach offers several advantages over other alternatives: (i) EMR retains enzymes more effectively than conventional packed bed reactors, (ii) operation with free enzyme avoids limitation of mass transfer associated with immobilization on carriers, and (iii) enzyme can be easily replenished during long term operation (Modin et al., 2014). To date, only a few studies have explored continuous biotransformation of TrOCs by EMR (Lloret et al., 2012; Nguyen et al., 2014a; Nguyen et al., 2014b). Lloret et al. (2012) reported high removal of phenolic TrOCs, namely estradiol and estrone; however, that study was conducted for only $8 \mathrm{~h}$. High and stable biotransformation of both bisphenol A and diclofenac by an EMR was demonstrated by Nguyen et al. (2014a). Nguyen et al. (2014b) investigated the removal of four non-phenolic compounds, namely diclofenac, carbamazepine, sulfamethoxazole, and atrazine, and proposed simultaneous dosing of mediator and activated carbon to enhance their removal efficiencies.

Most, if not all, studies to date on TrOC removal by EMR have focused on a few compounds at a time. For the establishment of a uniform database regarding EMR performance, investigation of a broader spectrum of TrOCs is imperative. Another aspect that requires further systematic investigation is the role of the membrane in enzymatic degradation of TrOCs in an EMR. Ultrafiltration membranes typically used in EMRs cannot retain TrOCs. However, enzyme gel layer, which typically forms on membrane surface, can adsorb the TrOCs. Thus the membrane may facilitate enzymatic degradation of TrOCs. A few studies have alluded to this aspect (Nguyen et al., 2014a; Nguyen et al., 2014b), however, any systematic study elucidating the phenomena involved, particularly the extent of adsorption and biodegradation during prolonged operation, has not been reported.

The objective of this study was to assess the performance of an EMR utilizing a commercially available laccase from Aspergillus oryzae for the removal of 30 chemically diverse TrOCs (e.g., phenolic/non-phenolic moieties and electron releasing/demanding substituent groups). Baseline batch tests provided valuable insight into the EMR performance. The effect of addition of redox-mediators, namely 1-hydroxybenzotriazole (HBT) or syringaldehyde (SA), on the enzymatic TrOC degradation was highlighted. Particularly, the complementary role of TrOC retention by the gel layer on the membrane and their enzymatic degradation was systematically elucidated. 


\section{Materials and Methods}

\subsection{TrOCs, laccase and mediators}

A synthetic wastewater containing a mixture of 30 TrOCs in Milli-Q water was prepared for this study. These compounds were selected due to their ubiquitous presence in wastewater and contaminated water bodies, and their range of chemical properties, e.g., phenolic/nonphenolic moieties and electron releasing/demanding substituent groups. Relevant physicochemical properties of these TrOCs appear in Supplementary Data Table S1. The TrOCs investigated were also chosen to represent various common classes of TrOCs, namely pharmaceutical and personal care products, industrial chemicals, steroid hormones and phytoestrogens, and pesticides,. In the batch tests, each TrOC concentration was $100 \mu \mathrm{g} / \mathrm{L}$, while the synthetic wastewater fed to the EMR contained each of the compounds at a concentration of $5 \mu \mathrm{g} / \mathrm{L}$, except for one run which was conducted at a TrOC concentration of $100 \mu \mathrm{g} / \mathrm{L}$ (see Section 2.3.3).

Laccase, purified from genetically modified Aspergillus oryzae, was obtained from Novozymes Australia Pty Ltd. According to the supplier, the molecular weight of this laccase is $56 \mathrm{kDa}$. It has a purity of approximately $10 \%(\mathrm{w} / \mathrm{w})$, density of $1.12 \mathrm{~g} / \mathrm{mL}$, and activity (measured using 2,6-dimethoxy phenol, DMP, as substrate) of $150,000 \mu \mathrm{M}_{(\mathrm{DMP})} / \mathrm{min}$. Laccase catalysed degradation of a target compound ('substrate') depends on the relative oxidation reduction potential (ORP) of that compound and laccase (Xu et al., 2000). The laccase used in this study had an ORP of $0.27 \mathrm{mV}$.

The mediators selected for this study i.e., syringaldehyde (SA) and 1-hydroxybenzotriazole (HBT), have been well characterized in the literature (Xu et al., 2000). SA is a small molecular weight phenolic compound, while HBT contains the structural group $=\mathrm{N}-\mathrm{OH}$. Both of these mediators work on hydrogen atom transfer mechanism. Oxidation of SA and HBT by laccase produces highly reactive radicals phenoxyl and aminoxyl, respectively.

TrOCs and mediators were obtained from Sigma-Aldrich (Australia). TrOC stock solution (1 $\mathrm{g} / \mathrm{L}$ each) was prepared in pure methanol, and stored at $-18^{\circ} \mathrm{C}$. The solution was used within a month. Separate stock solutions $(50 \mathrm{mM})$ of SA and HBT were prepared in Milli-Q water and stored at $4{ }^{\circ} \mathrm{C}$.

\section{$2.2 \quad$ Batch tests}


The test solution contained an enzymatic activity of $c a .180 \mu \mathrm{M}_{(\mathrm{DMP})} / \mathrm{min}$ (dilution of $30 \mu \mathrm{L}$ stock laccase solution by Milli-Q water to $25 \mathrm{~mL}$ ). An aliquot of the stock TrOC cocktail was added to the test solution to obtain an initial nominal concentration of $100 \mu \mathrm{g} / \mathrm{L}$ of each TrOCs. The impact of redox mediator addition on laccase degradation of TrOC was assessed by adding SA or HBT $(10 \mu \mathrm{M})$ to the test solution. The mediator concentration was selected following a baseline investigation with bisphenol A and diclofenac (Nguyen et al., 2014a). TrOCs in Milli-Q water (without laccase) served as control. The $\mathrm{pH}$ of the test solution was $6.8 \pm 0.2$. All the containers were covered and incubated at $25^{\circ} \mathrm{C}$ for $24 \mathrm{~h}$ in a rotary shaker (70 rpm). The experiments were conducted in triplicate. The whole test solution was collected for TrOC analysis at the end of the incubation period. The samples were diluted to $500 \mathrm{~mL}$, filtered through $0.45 \mu \mathrm{m}$ glass fiber filter, and $\mathrm{pH}$ immediately adjusted to 2 by adding $\mathrm{H}_{2} \mathrm{SO}_{4}(4 \mathrm{M})$.

\subsection{EMR system and operation protocol \\ 2.3.1 EMR setup}

The EMR system comprised a $1.5 \mathrm{~L}$ (active volume) glass reactor (Supplementary Data Figure S2). A hollow fiber membrane module (Microza Membranes, Pall Corporation, NSW, Australia) having a surface area of $0.19 \mathrm{~m}^{2}$ was used in the submerged configuration. The membrane was made of polyacrylonitrile. It was an ultrafiltration (UF) membrane having a molecular weight cut off of $6 \mathrm{kDa}$. The temperature of the reactor was maintained at $28{ }^{\circ} \mathrm{C}$ by placing it in a water bath equipped with a temperature controller (Heating immersion circulator, Julabo, Germany). A dissolved oxygen (DO) concentration of $3 \mathrm{mg} / \mathrm{L}$ was maintained in the EMR via air bubbling through a diffuser connected to an air pump. The $\mathrm{pH}$ of the reactor was steady at $6.8 \pm 0.2$ without any specific control. Transmembrane pressure (TMP) was constantly recorded with a precision of $\pm 0.1 \mathrm{kPa}$ by a pressure gauge (Extech Equipment Pty Ltd, Australia).

\subsubsection{EMR operation}

Retention of laccase by the UF membrane was confirmed as described in a previous study (Nguyen et al., 2014a). It is note-worthy that despite complete retention of laccase by the membrane, enzymatic activity can gradually diminish due to its denaturation by various physical, chemical and biological inhibitors such as the effect of shear stress (Modin et al., 2014). A protocol of 12 hourly laccase injections with a small dose (400 $\mu \mathrm{L}$ per litre of the 
reactor volume) was developed to sustain continuous operation. This was equivalent to a laccase dose of $46 \mathrm{mg} / \mathrm{L} \mathrm{d}$. Thus the laccase activity in the EMR was maintained at 170-190 $\mu \mathrm{M}_{\text {(DMP) }} / \min$ (Nguyen et al., 2014a; Nguyen et al., 2014b).

To start up the EMR, stock solution ( $2 \mathrm{~mL}$ ) of laccase was added to $1.5 \mathrm{~L}$ Milli-Q water. This resulted in an enzymatic activity of $c a .180 \mu \mathrm{M}_{(\mathrm{DMP})} / \mathrm{min}$ in the reactor. A peristaltic pump was used to operate the membrane intermittently ( $8 \mathrm{~min}$ on and $1 \mathrm{~min}$ off) at an average flux of $1.1 \mathrm{~L} / \mathrm{m}^{2} \mathrm{~h}$. This resulted in a hydraulic retention time (HRT) of $8 \mathrm{~h}$. Feed solution containing TrOCs at a concentration of $5 \mu \mathrm{g} / \mathrm{L}$ in Milli-Q water was continuously fed to the reactor. The EMR was first operated for $72 \mathrm{~h}$ (i.e., $9 \times$ HRT) without any mediator. After operating the EMR for a period of $4 \mathrm{x}$ HRT, collection of TrOC samples was initiated, and three sets of feed, supernatant and permeate samples were collected at equal intervals over the rest of the operation period. The mediator (SA or HBT) was continuously fed to the reactor, obtaining a final mediator concentration of $10 \mu \mathrm{M}$, to study the effect of mediator addition on enzymatic degradation of TrOC. To avoid any possible interaction between the mediators and TrOCs during the storage time in the feed tank, feed containing the TrOCs and mediators was prepared daily and added separately by two different pumps.

During continuous operation, beyond a TMP of $10 \mathrm{kPa}$ the UF membrane was backwashed in situ by Milli-Q water at a flux of $24 \mathrm{~L} / \mathrm{m}^{2} \mathrm{~h}(5 \mathrm{~s})$. An additional two-stage ex situ backwash (flux of $5 \mathrm{~L} / \mathrm{m}^{2} \mathrm{~h}$ ) was applied at the end of each run: the membrane was first backwashed with $1 \mathrm{~L}$ of Milli-Q water, and then by $1 \mathrm{~L}$ of $\mathrm{NaOCl}(500 \mathrm{mg} / \mathrm{L}$ active chlorine). After each ex situ Milli-Q water backwash, enzymatic activity measurement was conducted on samples from the cleaning solution to confirm the accumulation of enzyme on the membrane surface.

\subsubsection{Role of membrane and enzymatic degradation}

In an EMR, a gel layer can form on the membrane surface due to retention of the enzyme by the membrane. Such a gel layer may facilitate TrOC retention and possibly their subsequent enzymatic degradation. In order to clarify the role of the membrane gel layer, TrOC removal performance of the EMR with addition of active and heat-inactivated laccase (laccase incubated at $80{ }^{\circ} \mathrm{C}$ for $10 \mathrm{~min}$ ) was compared. Four TrOCs (i.e., pentachlorophenol, oxybenzone, ibuprofen and benzophenone) which represented a group of compounds showing high removal by the EMR (see section 3.2.2) were selected for this investigation. To reach the adsorption capacity of the enzyme gel layer, TrOC concentration in feed was 
increased to $100 \mu \mathrm{g} / \mathrm{L}$ of each compound for this investigation. All other parameters were kept the same as described in Section 2.3.2.

\subsection{Analytical methods}

\subsubsection{TrOC analysis}

TrOC concentration was measured by a GC/MS system (QP5000, Shimadzu, Japan) following a previously reported method (Hai et al., 2011a). The detection limits were TrOCspecific and ranged between 1-20 ng/L (Supplementary data table S1). Additionally, the concentration of the four TrOCs noted in Section 2.3.3 (i.e., pentachlorophenol, oxybenzone, ibuprofen and benzophenone) was measured by a HPLC - UV-vis detector system (Shimadzu, Japan) following a previously reported method (Hai et al., 2011b) as described in Supplementary Data Table S3. The removal efficiency was calculated as $R=100 \times\left(1-\frac{C_{E f f}}{C_{I n f}}\right)$ , where $\mathrm{C}_{\text {Inf }}$ and $\mathrm{C}_{\mathrm{Eff}}$ are influent and effluent (permeate) concentrations of the TrOC, respectively. The Student's $t$-test was used to verify if the mean removal efficiency of a specific TrOC from two sets of experiments (e.g., removal by EMR with/without mediator) was statistically different (i.e., $p<0.05$ ).

\subsubsection{Enzymatic activity, ORP and toxicity assay}

Laccase activity was assayed by recording the change in absorbance $(468 \mathrm{~nm})$ due to oxidation of 2,6-dimethoxyl phenol (DMP) in the presence of sodium citrate ( $\mathrm{pH} 4.5$ ). Enzymatic activity was calculated using a molar extinction coefficient of $49.6 / \mathrm{mM} \mathrm{cm}$ and expressed in $\mu \mathrm{M}_{(\mathrm{DMP})} / \mathrm{min}$. The ORP of the laccase solution before and after mediator addition was measured utilizing an ORP meter (WP-80D dual pH-mV meter, Thermo Fisher Scientific, Australia). Bacterial toxicity of influent and effluent (permeate) was analysed in duplicate by measuring bioluminescence inhibition in Photobacterium leiognathi, and expressed as relative Toxic Unit (rTU) (Nguyen et al., 2014a).

\section{Results and discussion}

\subsection{TrOC degradation capacity of the laccase utilized}

Together with a few compounds (i.e., bisphenol A, estradiol, estrone, diclofenac, atrazine and carbamazepine) that have been recently investigated (Lloret et al., 2012; Nguyen et al., 2014a; Nguyen et al., 2014b), this study included a broad spectrum of TrOCs to establish a 
comprehensive understanding of the degradation capacity of the laccase preparation used. The batch test data regarding laccase catalysed degradation of the selected TrOCs provided important baseline information to explain EMR performance. Given the difference in the chemical structures of the TrOCs in this study (phenolic/non-phenolic moieties and the presence of electron releasing/demanding functional groups), as expected, a significant variation in their enzymatic degradation was observed (Table 1). Laccase efficiently degrades compounds with phenolic moiety. Thus high degradation of all phenolic TrOCs except salicylic acid, formononetin, pentachlorophenol, enterolactone and oxybenzone was achieved. In contrast, laccase could not efficiently remove non-phenolic compounds except octocrylene and diclofenac ( 31 and $41 \%$ removal, respectively).

\section{[TABLE 1]}

All steroid hormones and the industrial chemicals tested were phenolic compounds and thus well degraded. Similarly, the phenolic personal care product triclosan was efficiently degraded. However, despite being phenolic compounds, none of the phytoestrogens (i.e, enterolactone and formononetin) were degraded by laccase. The low enzymatic degradation of a few of the phenolic compounds identified in Table 1 will be discussed later in this section. With the exception of octocrylene and diclofenac, none of the non-phenolic compounds were enzymatically degraded. Indeed, consistent with the literature (Hai et al., 2012a; Tran et al., 2013; Yang et al., 2013), all pesticides (including pentachlorophenol, which is a phenolic compound) demonstrated particular resistance to degradation. All the pharmaceuticals, except salicylic acid, were non-phenolic compounds and thus underwent negligible enzymatic degradation. A similar observation could be made with all of the UVfilters (personal care product).

The low or negligible removal of non-phenolic compounds reported in Table 1 is consistent with a previous study where the crude enzyme extract from Trametes versicolor was used (Nguyen et al., 2014c). The observed low removal may be explained by the presence of strong electron demanding groups or absence of strong electron releasing groups in the TrOC structure. Tadkaew et al. (2011) reported that the presence of electron demanding groups (e.g., amide $\left(-\mathrm{CONR}_{2}\right)$, carboxylic $(-\mathrm{COOH})$, and halogen $\left.(-\mathrm{X})\right)$ renders the compounds resistant to oxidation. The high removal of the non-phenolic TrOC diclofenac may have been due to the electron releasing functional group aromatic amine in its structure. Similarly, direct 
oxidation of diclofenac by laccase was reported by Lloret et al. (2012), who anticipated that laccase degradation of diclofenac is initiated with the aniline group.

Despite the usual high amenability of phenolic compounds to laccase degradation, in this study, a few phenolic TrOCs, namely salicylic acid, formononetin, pentachlorophenol, enterolactone and oxybenzone were degraded inefficiently. The observed low removal of these compounds may be due to deficient oxidative capacity of the laccase, which depends on the ORP difference between the TrOC and laccase, and/or steric hindrance. For example, while testing the electrochemical behaviour of natural phenolics, Simić et al. (2007) reported that the ORP of salicylic acid is $0.94 \mathrm{~V}$, which is significantly higher than the ORP of the laccase used in this study $(0.28 \mathrm{~V})$. In contrast, d'Acunzo et al. (2006) observed that some phenolic compounds such as $\beta$-naphthols and 2,4,6-trichlorophenol were not oxidized by laccase due to steric hindrance. They explained that the presence of electron demanding groups (sterically demanding groups) at ortho position to the $-\mathrm{OH}$ group can hinder the approach of the substrate to the active sites of laccase. Consistent with that explanation, in the current study, among the poorly removed phenolic TrOCs, salicylic acid, pentachlorophenol and oxybenzone contain EWG at the ortho position. Notably, similar to this study, Jeon et al. (2008) observed poor degradation of pentachlorophenol by laccase (from Ganoderma lucidum). Conversely, Ullah et al. (2000) reported complete degradation of pentachlorophenol by laccase (from Coriolus versicolor). This contradiction may be explained by the difference in ORP of laccase derived from different sources $(\mathrm{Xu}$ et al., 2000).

\subsection{TrOC removal performance of the laccase-EMR}

\subsubsection{Overall TrOC removal and the role of membrane}

TrOC degradation data from batch and continuous EMR experiments cannot be directly compared due to the difference in the operation modes. However, two distinct patterns in the TrOC degradation profile for the EMR (Figure 1) are worth noting: (i) significantly higher removal of some phenolic and non-phenolic TrOCs, with low but discernible improvement in removal of some other non-phenolic compounds, (ii) lower removal (although still maintaining at $40-90 \%$ ) of some phenolic compounds which were well degraded in batch tests.

[FIGURE 1] 
Compared to the batch test results, lower (although significant) removal of some compounds (i.e., estrone, 4-tert-butyphenol, bisphenol A, 17 $\alpha$-ethinylestradiol, estriol and 17 $\beta$-estradiol) during the continuous operation of the EMR may be attributed to the sustained TrOC-loading to the EMR, and is not entirely unexpected (Lloret et al., 2012). Of particular interest was the better removal $(p<0.05$, Supplementary Data Table S4) achieved by the EMR for five phenolic and five non-phenolic TrOCs (Figure 1). The UF membrane used in this study was not expected to retain any TrOC by size exclusion. The EMR was operated in the absence of the enzyme to determine TrOC adsorption directly on the membrane surface. Results show that $\mathrm{TrOC}$ removal by adsorption on the membrane was negligible $(<5 \%)$. However, when an enzyme solution is flushed through an UF membrane that rejects the enzyme molecules, the enzyme can form a porous, thin gel layer ('secondary membrane') on the membrane (Modin et al., 2014). Wastewater-borne suspended and colloidal particles as well as water soluble macromolecules may co-deposit on the gel layer and enhance removal of pollutants (Hai et al., 2012b). Therefore, it was hypothesized that the improved removal was due to the retention of TrOCs by an enzyme gel layer dynamically formed on the membrane, followed possibly by enzymatic degradation. Indeed high laccase activity was detected in the cleaning solution from ex situ Milli-Q water backwashing (Section 2.3.2). A litre of cleaning solution was generated in each Milli-Q backwah, and the enzymatic activity in that solution was $60 \mu \mathrm{M}_{(\mathrm{DMP})} / \mathrm{min}$. This translates to an accumulation of $c a .0 .24 \mathrm{~g}$ laccase $/ \mathrm{m}^{2}$ membrane surface, evidencing formation of a laccase gel layer on the membrane surface. Furthermore, for the TrOCs which received significantly higher removal by the EMR (i.e., salicylic acid, formononetin, pentachlorophenol, enterolactone and oxybenzone), the ratio of the concentration in permeate and supernatant (P/S ratio) was significantly below 1 (Figure 2), confirming that TrOCs were indeed retained by the gel layer of laccase on the membrane.

\section{[FIGURE 2]}

Of the TrOCs shown in Figure 2, pentachlorophenol, oxybenzone, benzophenone and octocrylene were all significantly hydrophobic (as indicated by $\log D_{\mathrm{pH}=7}$ values greater than 3 ) and showed high retention on the membrane (P/S ratios $0.44 \pm 0.15, n=15)$. These compounds also showed high improvement $(49-84 \%)$ in removal by the EMR compared to batch test removal (Figure 1). In contrast, enterolactone, gemfibrozil, naproxen and ketoprofen, which are hydrophilic ( $\log D_{\mathrm{pH}=7}$ values ranging from $0.19-1.89$ ), had $\mathrm{P} / \mathrm{S}$ ratios of $0.79 \pm 0.1(\mathrm{n}=12)$, and were still better removed by the EMR compared to the batch test removal, but to a lesser extent $(10-17 \%)$. These observations strongly point to the 
importance of hydrophobicity for retention of these TrOCs on the membrane gel layer, which consequently governed their overall removal by the EMR. However, a few of the TrOCs plotted in Figure 2 (i.e., salicylic acid, formononetin, ibuprofen, ametryn and amitriptyline) as well as the TrOCs that showed somewhat lower removal by the EMR than in the batch tests (Figure 1), did not conform to the trend of high hydrophobicity effecting high membrane retention (low $\mathrm{P} / \mathrm{S}$ ratio) and high EMR removal, or vice versa. For example, compared to batch tests, high improvement in removal of salicylic acid was observed by the EMR although it was highly hydrophilic $\left(\log D_{\mathrm{pH}=7}=-1.13\right)$. Conversely, despite having a high $\log$ $D_{\mathrm{pH}=7}$ of $4.11,17 \alpha$-ethinylestradiol was removed with an efficiency of around $80 \%$ by the EMR as compared to complete removal in batch tests. Taken together, these observations indicate the following possibilities: (i) TrOC retention on membrane gel layer was governed not only by hydrophobic partitioning but also by non-hydrophobic interactions such as electrostatic interactions (Luo et al., 2014), (ii) both retention on membrane and enzymatic degradation was important. Further discussion on the latter aspect follows in Section 3.2.2.

The formation of the enzyme gel layer on the membrane may lead to gradual fouling and drop in permeate flux (Lloret et al., 2012; Modin et al., 2014). In order to keep the focus of this study on assessment of TrOC removal mode, a low flux of $1.1 \mathrm{~L} / \mathrm{m}^{2} \mathrm{~h}$ was applied. Under the operating conditions in this study, a TMP increase rate of $3.3 \mathrm{kPa} / \mathrm{d}$ was observed (Supplementary Data Figure S5), and a mild in situ backwash on every third day as per the protocol described in Section 2.3 was adequate to reinstate the TMP to its original value. Although beyond the scope of this study, further work to establish the applicable flux-range as a function of feed wastewater characteristics would be interesting.

\subsubsection{Fate of TrOC following membrane retention}

The data presented in Figures 1 and 2 show a complementary role of TrOC retention by the membrane gel layer and enzymatic degradation. In order to provide further evidence, EMR performance with active laccase and heat-inactivated laccase was compared. For this set of experiments, four TrOCs (two phenolics, i.e., pentachlorophenol and oxybenzone, and two non-phenolics i.e., ibuprofen and benzophenone), which showed significant retention on the membrane (low P/S ratio) were selected.

When the EMR was operated with inactivated laccase, a significant amount of TrOCs was initially adsorbed on the laccase gel layer as evidenced by stable removal of TrOCs for nearly 
$2 \mathrm{~d}$ (Figure 3). However, thenceforth, the removal efficiency gradually diminished. The saturation of the adsorption capacity of the layer of enzyme (inactivated) on the membrane was evidenced by the $\mathrm{P} / \mathrm{S}$ ratio gradually approaching unity. In contrast, a significantly high and stable removal of these compounds was sustained by the EMR when operated with the addition of active laccase (Figure 3). Thus it was concluded that TrOCs retained by the enzyme gel layer were eventually degraded.

\section{[FIGURE 3]}

Previous studies have reported short-term increase in organics removal due to pre-formed adsorbent-coating on membrane, or dynamically formed adsorbent layer on membrane, although the role of biodegradation was not addressed (Heijman et al., 2009; Löwenberg et al., 2014). By contrast, a few studies have shown the advantages of adding adsorbents to membrane bioreactors to effect simultaneous adsorption, retention on membrane cake layer and biodegradation (Hai et al., 2012b; Nguyen et al., 2014d). Li and Loh (2007) developed a hollow fibre membrane reactor wherein microbes were entrapped within the fibres. They achieved improved removal of phenol when granular activated carbon too was incorporated into the membrane structure. Conversely, various enzymes can be immobilized on membranes, thereby facilitating conversion of resistant chemicals concurrent with the retention of the insoluble metabolites (Gasser et al., 2014; Hou et al., 2014). The uniqueness of this study is that it systematically demonstrates improved degradation of a range of TrOCs by dynamically immobilized laccase on the UF membrane.

\subsection{EMR performance with mediator addition}

Laccase-mediator systems can generate free radicals having higher redox potential than laccase itself. Furthermore, these radical species can act as a carrier of electrons between laccase and the substrate, thereby overcoming the steric hindrance that may exist between them (Xu et al., 2000). In a batch test study by Weng et al. (2012), dosing of SA to laccase led to concomitant increase in ORP of the solution and degradation of sulphonamide antibiotics. In the current study, the ORP of the laccase solution increased significantly from $0.27 \mathrm{~V}$ to 0.53 and $0.48 \mathrm{~V}$, due to addition of SA and HBT, respectively. Accordingly the substrate spectrum was observed to be broadened and higher TrOC removal by the EMR could be obtained due to mediator dosing to the EMR (Figure 4).

\section{[FIGURE 4]}

\subsubsection{Substrate specificity}


The aspect of mediator addition to improve TrOC degradation by EMR has been communicated in a limited number of studies (Nguyen et al., 2014a; Nguyen et al., 2014b). In our previous study involving four non-phenolic TrOCs, SA addition to an EMR resulted in a significant improvement of TrOC removal depending on the properties and loading rates of the TrOCs (Nguyen et al., 2014b). The current study compares performance of SA and HBT for a larger set of TrOCs. A notable observation was the substrate-specificity demonstrated by the mediators. For example, SA addition achieved better removal of phenolic compounds namely, estrone, 4-tert-bytylphenol and bisphenol A $(p<0.05$, Supplementary Data Table S4). Conversely HBT achieved better removal of non-phenolic compounds, namely clofibric acid, atrazine, primidone, and carbamazepine ( $p<0.05$, Supplementary Data Table S4). Overall, HBT appeared to offer more versatility i.e., effective degradation of both phenolic and non-phenolic TrOCs (Figure 4).

Substrate specificity of mediators has been reported before, but only in conjunction with batch tests (Camarero et al., 2005; Nguyen et al., 2014c). The efficiency of a laccasemediator system depends not only on the ORP of the radicals generated, but also on reversibility of the reaction of the radicals with the substrate, and the stability of the radicals generated (Camarero et al., 2005). However, both SA and HBT act via the same oxidation mechanism (i.e., hydrogen atom transfer), and the ORP of the laccase preparation with addition of the mediators (separately) were similar. Thus the performance difference between the mediators may be explained by the overall stability of the highly reactive radicals formed. Phenoxyl radicals are generated due to laccase oxidation of SA, and these radicals have been reported to be more active than aminoxyl radicals generated from HBT. Conversely, phenoxyl radicals are extremely unstable and convert to much less active quinone $\mathrm{Xu}$ et al., 2000). While the aminoxyl radicals generated from HBT also turn rapidly to benzotriazole and other inactive compounds, their reactivity and stability appears to be better balanced than that of phenoxyl radicals (Xu et al., 2000).

\subsubsection{Laccase-mediator system: Batch vs. EMR application}

An ideal redox-mediator must not be consumed during the reaction. However, as noted above, phenoxyl and aminoxyl radicals can convert to quinone and benzotriazole, respectively (Xu et al., 2000), which are far less efficient as mediators. Thus, it is necessary to continuously add the mediators to maintain a stable removal. For example, Hata et al. 
(2010) achieved 40\% increase in the removal of carbamazepine by adding HBT every $8 \mathrm{~h}$ to the reactor. In the current study, a marked additional improvement in TrOC removal by the EMR (continuous mediator dosing) was achieved (Figure 4) when compared with the improvement achieved during batch incubation tests (Supplementary Data Figure S6). This is evidenced by the distinct removal-improvement profiles (batch vs. EMR) of seven highly resistant TrOCs shown in Figure 5 for HBT as an example.

Figure 6 provides further unique insight to the plausible reasons for the better removal by the EMR. Of the seven TrOCs plotted in Figure 6, for atrazine and carbamazepine, significant improvement in removal due to HBT dosing to EMR was accompanied by a significant drop in their reactor-supernatant concentrations, evidencing better degradation capacity of the laccase-HBT system. For the rest of the TrOCs, however, little difference in reactorsupernatant concentration was observed (i.e., less amenable to laccase-HBT system than atrazine or carbamazepine), although significant improvement in their removal by the EMR was obtained when HBT was added. Consistent with the discussion in Section 3.2, the observations made here strongly point to a complementary role of enhanced degradation by the laccase-mediator system and membrane retention, and also that for certain compounds which are less amenable to mediator-enhanced enzymatic degradation (i.e., clofibric acid, metronidazole, fenoprop, gemfibrozil and primidone) among the compounds shown in Figure 6) membrane retention has a more profound impact on the overall removal.

[FIGURE 5]

[FIGURE 6]

\subsection{Effluent toxicity}

Despite efficient degradation of the target compounds, increased effluent toxicity may be observed following enzymatic treatment (Marco-Urrea et al., 2009; Nguyen et al., 2014c). This has been attributed to metabolites produced during TrOC degradation and/or highly reactive radical species generated from oxidation of mediators (Kim and Nicell, 2006). Because a set of 30 TrOCs was used in this study, it was not possible to relate the metabolites to their parent compounds. Thus, the toxicity of the effluent to a bacterial system was quantified as a measure of the overall toxicity of metabolites and reactive radical species generated via the mediator-enhanced laccase system. 
There was a small but insignificant increase in toxicity following treatment by the laccaseEMR (feed toxicity $4.1 \pm 0.43$ rTU vs. permeate toxicity $7.0 \pm 1.8$ rTU, $n=2$ ), indicating that the laccase-treatment did not generate toxic by-products. Furthermore, there was no detectable increase in toxicity in the treated solution after addition of $10 \mu \mathrm{M}$ of either SA or HBT to the EMR. This is consistent with HBT results from previous batch tests (Nguyen et al., 2014c), but suggests that SA addition to EMR may cause slightly less toxicity than previously thought (Nguyen et al., 2014a; Nguyen et al., 2014b). The slight discrepancy in case of SA may be due to the fact that in the previous EMR studies fewer numbers of TrOCs but with higher dosage were tested (Nguyen et al., 2014a; Nguyen et al., 2014b). However, the investigations conducted within the scope of this study confirm efficient degradation of a range of TrOCs by the EMR without causing significantly elevated toxicity in treated effluent

\section{Conclusion}

Batch tests with a diverse set of 30 TrOCs revealed laccase-catalysed degradation of nine out of 14 phenolic and only two out of 16 non-phenolic compounds. The ORP of the laccase solution almost doubled due to addition of the mediators (SA or HBT); however, this led to better degradation of only one phenolic and three non-phenolic TrOCs. Compared to the batch tests, the EMR was observed to facilitate degradation of a number of TrOCs originally showing resistance to enzymatic degradation. This was attributed to the formation of a dynamic layer of laccase over the membrane surface which retained TrOCs and facilitated their subsequent enzymatic degradation. A complementary role of enhanced degradation by the laccase-mediator system and retention by the membrane gel layer was revealed. Membrane retention particularly enhanced the degradation of the compounds which are less amenable to mediator-enhanced enzymatic degradation.

\section{Acknowledgement}

Dr. Faisal I. Hai acknowledges research grants from GeoQuEST Research Centre (University of Wollongong). A PhD scholarship to Luong N. Nguyen from the University of Wollongong is greatly appreciated. Novozymes Pty. Ltd, Australia is thanked for the provision of enzyme solution.

\section{References}

Cabana, H., Jones, J. P. \& Agathos, S. N. 2007. Elimination of endocrine disrupting chemicals using white rot fungi and their lignin modifying enzymes: A review. Engineering in Life Sciences, 7, 429-456. 
Camarero, S., Ibarra, D., Martínez, M. J. \& Martínez, Á. T. 2005. Lignin-derived compounds as efficient laccase mediators for decolorization of different types of recalcitrant dyes. Applied and Environmental Microbiology, 71, 1775-1784.

d'Acunzo, F., Galli, C., Gentili, P. \& Sergi, F. 2006. Mechanistic and steric issues in the oxidation of phenolic and non-phenolic compounds by laccase or laccase-mediator systems. The case of bifunctional substrates. New J. Chem., 30, 583-591.

Gasser, C., Yu, L., Svojitka, J., Wintgens, T., Ammann, E., Shahgaldian, P., Corvini, P. X. \& Hommes, G. 2014. Advanced enzymatic elimination of phenolic contaminants in wastewater: a nano approach at field scale. Applied Microbiology and Biotechnology, 98, 3305-3316.

Hai, F. I., Tessmer, K., Nguyen, L. N., Kang, J., Price, W. E. \& Nghiem, L. D. 2011 a. Removal of micropollutants by membrane bioreactor under temperature variation. Journal of Membrance Science, 383, 144-151.

Hai, F. I., Li, X., Price, W. E. \& Nghiem, L. D. 2011b. Removal of carbamazepine and sulfamethoxazole by MBR under anoxic and aerobic conditions. Bioresource Technology, 102, 10386-10390.

Hai, F. I., Modin, O., Yamamoto, K., Fukushi, K., Nakajima, F. \& Nghiem, L. D. 2012 a. Pesticide removal by a mixed culture of bacteria and white-rot fungi. Journal of the Taiwan Institute of Chemical Engineers, 43, 459-462.

Hai, F. I., Yamamoto, K., Nakajima, F. \& Fukushi, K. 2012b. Application of a GAC-coated hollow fiber module to couple enzymatic degradation of dye on membrane to whole cell biodegradation within a membrane bioreactor. Journal of Membrane Science, 389, 67-75.

Hata, T., Shintate, H., Kawai, S., Okamura, H. \& Nishida, T. 2010. Elimination of carbamazepine by repeated treatment with laccase in the presence of 1 hydroxybenzotriazole. Journal of Hazardous Materials, 181, 1175-1178.

Heijman, S. G. J., Hamad, J. Z., Kennedy, M. D., Schippers, J. \& Amy, G. 2009. Submicron powdered activated carbon used as a pre-coat in ceramic micro-filtration. Desalination and Water Treatment, 9, 86-91.

Hou, J., Dong, G., Ye, Y. \& Chen, V. 2014. Enzymatic degradation of bisphenol-A with immobilized laccase on $\mathrm{TiO}_{2}$ sol-gel coated PVDF membrane. Journal of Membrane Science, 469, 19-30.

Jeon, J.-R., Murugesan, K., Kim, Y.-M., Kim, E.-J. \& Chang, Y.-S. 2008. Synergistic effect of laccase mediators on pentachlorophenol removal by Ganoderma lucidum laccase. Applied Microbiology and Biotechnology, 81, 783-790.

Kim, Y.-J. \& Nicell, J. A. 2006. Laccase-catalysed oxidation of aqueous triclosan. Journal of Chemical Technology \& Biotechnology, 81, 1344-1352.

Li, Y. \& Loh, K. 2007. Hybrid-Hollow-Fiber Membrane Bioreactor for Cometabolic Transformation of 4-Chlorophenol in the Presence of Phenol. Journal of Environmental Engineering, 133, 404-410.

Lloret, L., Eibes, G., Feijoo, G., Moreira, M. T. \& Lema, J. M. 2012. Degradation of estrogens by laccase from Myceliophthora thermophila in fed-batch and enzymatic membrane reactors. Journal of Hazardous Materials, 213-214, 175-183.

Löwenberg, J., Zenker, A., Baggenstos, M., Koch, G., Kazner, C. \& Wintgens, T. 2014. Comparison of two PAC/UF processes for the removal of micropollutants from wastewater treatment plant effluent: Process performance and removal efficiency. Water Research, 56, 26-36.

Luo, Y., Guo, W., Ngo, H. H., Nghiem, L. D., Hai, F. I., Zhang, J., Liang, S. \& Wang, X. C. 2014. A review on the occurrence of micropollutants in the aquatic environment and 
their fate and removal during wastewater treatment. Science of The Total Environment, 473-474, 619-641.

Marco-Urrea, E., Pérez-Trujillo, M., Vicent, T. \& Caminal, G. 2009. Ability of white-rot fungi to remove selected pharmaceuticals and identification of degradation products of ibuprofen by Trametes versicolor. Chemosphere, 74, 765-772.

Modin, O., Hai, F. I., Nghiem, L. D. \& Basile, A. 2014. Gas-diffusion, extractive, and biocatalytic membrane biological reactors. In: Hai, F. I., Yamamoto, K. \& Lee, C.-H. (eds.) Membrane Biological reactors. UK (ISBN:971780400655): IWA publishing.

Nguyen, L. N., Hai, F. I., Price, W. E., Leusch, F. D. L., Roddick, F., McAdam, E. J., Magram, S. F. \& Nghiem, L. D. 2014a. Continuous biotransformation of bisphenol A and diclofenac by laccase in an enzymatic membrane reactor. International Biodeterioration \& Biodegradation, 95, 25-32.

Nguyen, L. N., Hai, F. I., Price, W. E., Leusch, F. D. L., Roddick, F., Ngo, H. H., Guo, W., Magram, S. F. \& Nghiem, L. D. 2014b. The effects of mediator and granular activated carbon addition on degradation of trace organic contaminants by an enzymatic membrane reactor. Bioresource Technology, 167, 169-177.

Nguyen, L. N., Hai, F. I., Nghiem, L. D., Kang, J., Price, W. E., Park, C. \& Yamamoto, K. 2014c. Enhancement of removal of trace organic contaminants by powdered activated carbon dosing into membrane bioreactors. Journal of the Taiwan Institute of Chemical Engineers, 45, 571-578.

Nguyen, L. N., Hai, F. I., Kang, J., Leusch, F. D. L., Roddick, F., Magram, S. F., Price, W. E. \& Nghiem, L. D. 2014d. Enhancement of trace organic contaminant degradation by crude enzyme extract from Trametes versicolor culture: Effect of mediator type and concentration. Journal of the Taiwan Institute of Chemical Engineers, 45, 1855-1862.

Schwarzenbach, R. P., Escher, B. I., Fenner, K., Hofstetter, T. B., Johnson, C. A., von Gunten, U. \& Wehrli, B. 2006. The Challenge of Micropollutants in Aquatic Systems. Science, 313, 1072-1077.

Simić, A., Manojlović, D., Šegan, D. \& Todorović, M. 2007. Electrochemical behavior and antioxidant and prooxidant activity of natural phenolics. Molecules, 12, 2327-2340.

Tadkaew, N., Hai, F. I., McDonald, J. A., Khan, S. J. \& Nghiem, L. D. 2011. Removal of trace organics by MBR treatment: The role of molecular properties. Water Research, 45, 2439-2451.

Tran, N. H., Hu, J. \& Urase, T. 2013. Removal of the insect repellent N,N-diethyl-mtoluamide (DEET) by laccase-mediated systems. Bioresource Technology, 147, 667671.

Ullah, M. A., Bedford, C. T. \& Evans, C. S. 2000. Reactions of pentachlorophenol with laccase from Coriolus versicolor. Applied Microbiology and Biotechnology, 53, 230 234.

Weng, S.-S., Ku, K.-L. \& Lai, H.-T. 2012. The implication of mediators for enhancement of laccase oxidation of sulfonamide antibiotics. Bioresource Technology, 113, 259-264.

Xu, F., Kulys, J. J., Duke, K., Li, K., Krikstopaitis, K., Deussen, H.-J. W., Abbate, E., Galinyte, V. \& Schneider, P. 2000. Redox chemistry in laccase-catalyzed oxidation of N-hydroxy compounds. Applied and Environmental Microbiology, 66, 2052-2056.

Yang, S., Hai, F. I., Nghiem, L. D., Price, W. E., Roddick, F., Moreira, M. T. \& Magram, S. F. 2013. Understanding the factors controlling the removal of trace organic contaminants by white-rot fungi and their lignin modifying enzymes: a critical review. Bioresource Technology, 141, 97-108. 


\section{LIST OF FIGURES}

Figure 1: Removal efficiency of $30 \mathrm{TrOCs}$ by the laccase-EMR as compared to batch test data. Laccase activity was maintained by the addition of $400 \mu \mathrm{L}$ of the commercial laccase solution per liter of the reactor volume every $12 \mathrm{~h}$ (equivalent to a laccase dose of $46 \mathrm{mg} / \mathrm{L}$ d). The EMR was operated for $72 \mathrm{~h}$ (i.e., 9 x HRT). Data presented as average \pm standard deviation $(n=3)$ in both batch and the EMR studies.

Figure 2: Concentration ratio in membrane permeate and reactor supernatant $(\mathrm{P} / \mathrm{S}$ ratio $)$ for TrOCs showing a better removal by laccase-EMR (compared to that in batch test). Data presented as average \pm standard deviation $(n=3)$.

Figure 3: Removal efficiency and concentration ratio (P/S ratio) profiles of four selected TrOCs during the operation of the laccase-EMR with heat-inactivated or active laccase. The EMRs were operated for a period of $18 \times$ HRT to confirm the dominant role of enzymatic degradation.

Figure 4: Enhancement of TrOC removal by the EMR due to the addition of mediators (SA or HBT) at a concentration of $10 \mu \mathrm{M}$ to the laccase-EMR. Laccase activity was maintained by the addition of $400 \mu \mathrm{L}$ of the commercial laccase solution per liter of the reactor volume every $12 \mathrm{~h}$ (equivalent to a laccase dose of $46 \mathrm{mg} / \mathrm{L} \mathrm{d}$ ). The EMR was operated for $72 \mathrm{~h}$ (i.e., $9 \mathrm{x}$ HRT). Data presented as average \pm standard deviation $(\mathrm{n}=3)$.

Figure 5: Comparison of the TrOC removal improvement (\%) due to HBT addition in batch tests and continuous operation of EMR demonstrating that mediator addition was more effective in case of the EMR operation. Data presented as average \pm standard deviation $(n=3)$.

Figure 6: Supernatant concentration of resistant non-phenolic TrOCs during the operation of the laccase-EMR with and without HBT dosing, and corresponding improvement (\%) in TrOC removal during HBT dosing. Data presented as average \pm standard deviation $(n=3)$. 


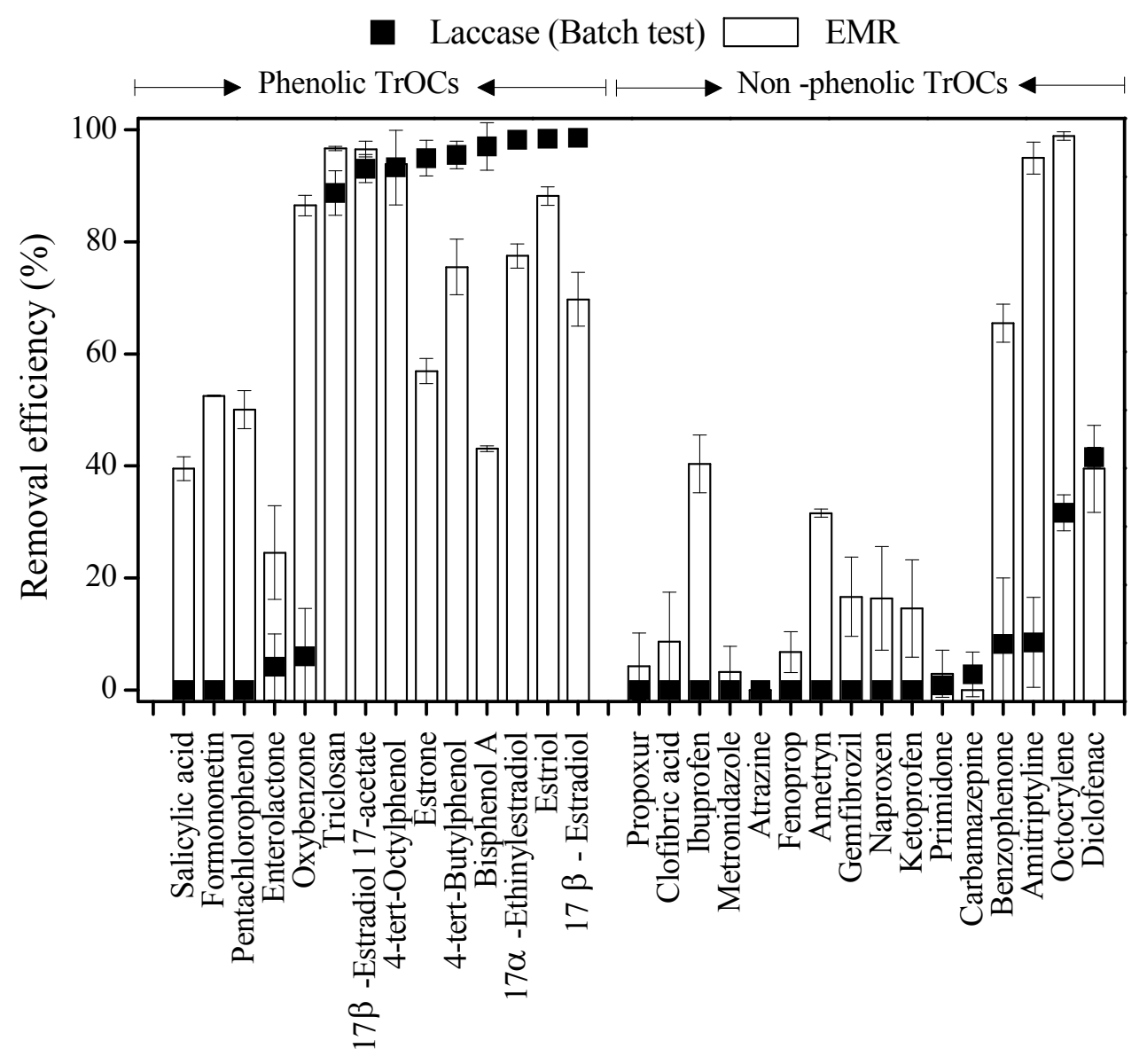

Figure 1 


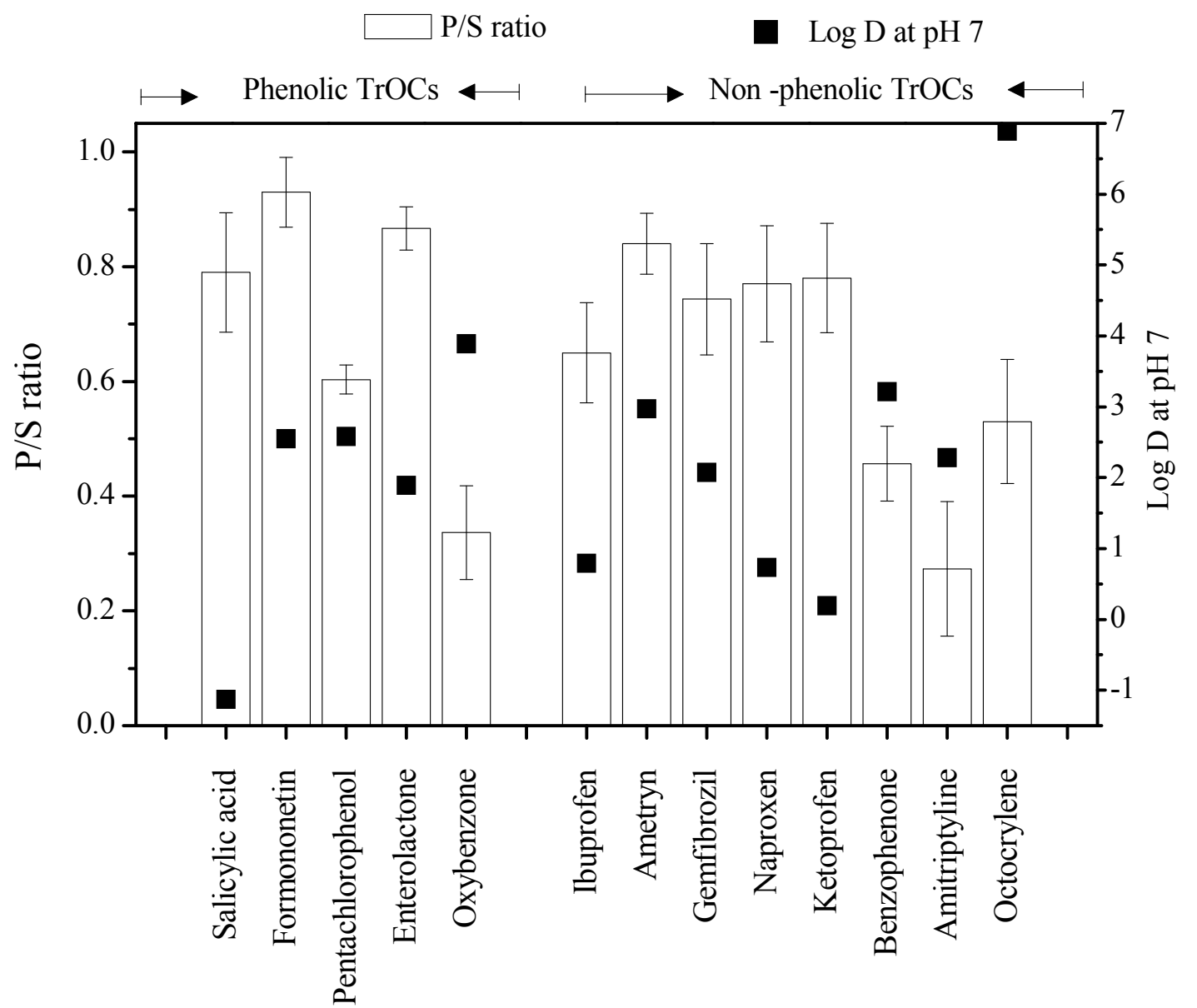

Figure 2 


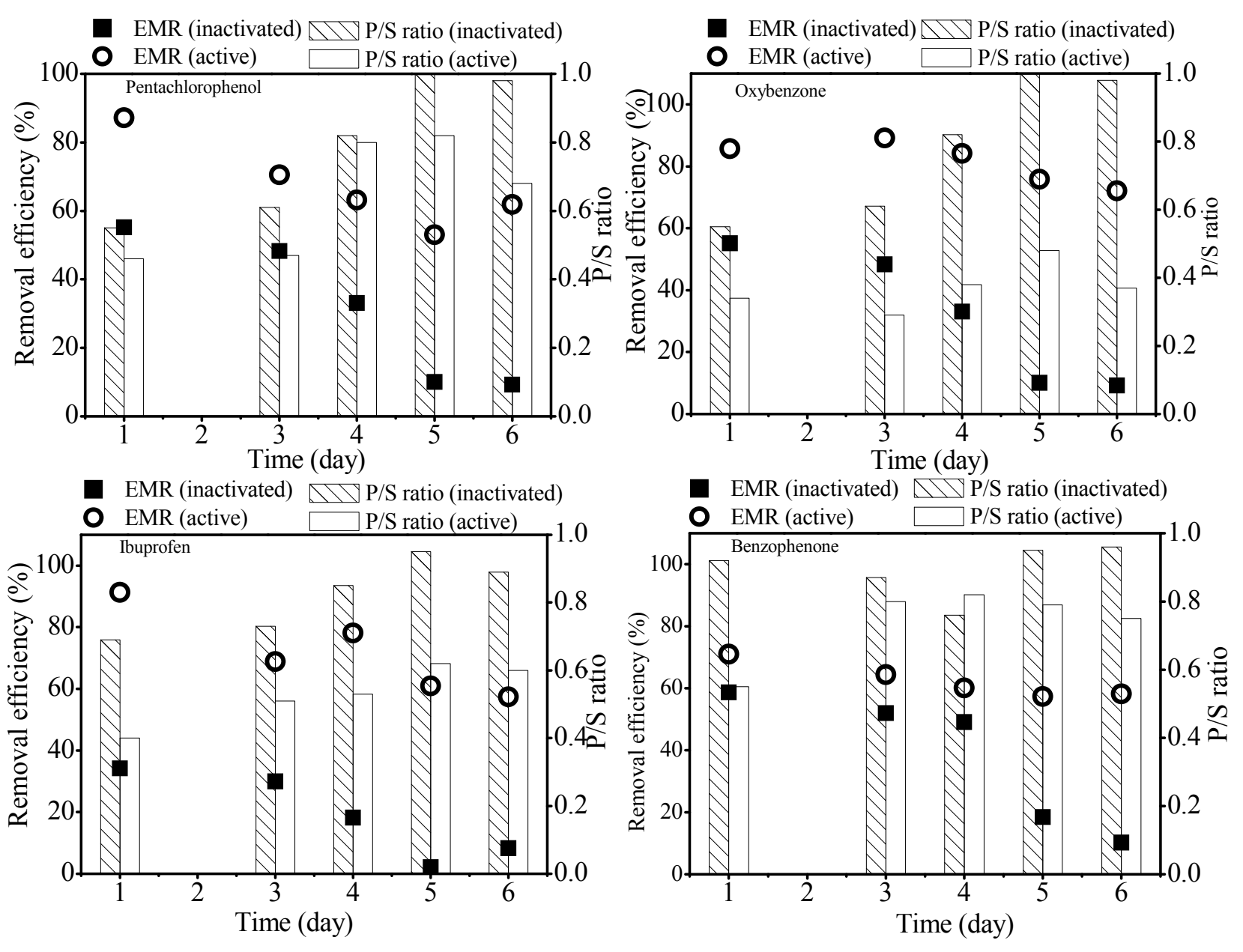

Figure 3 


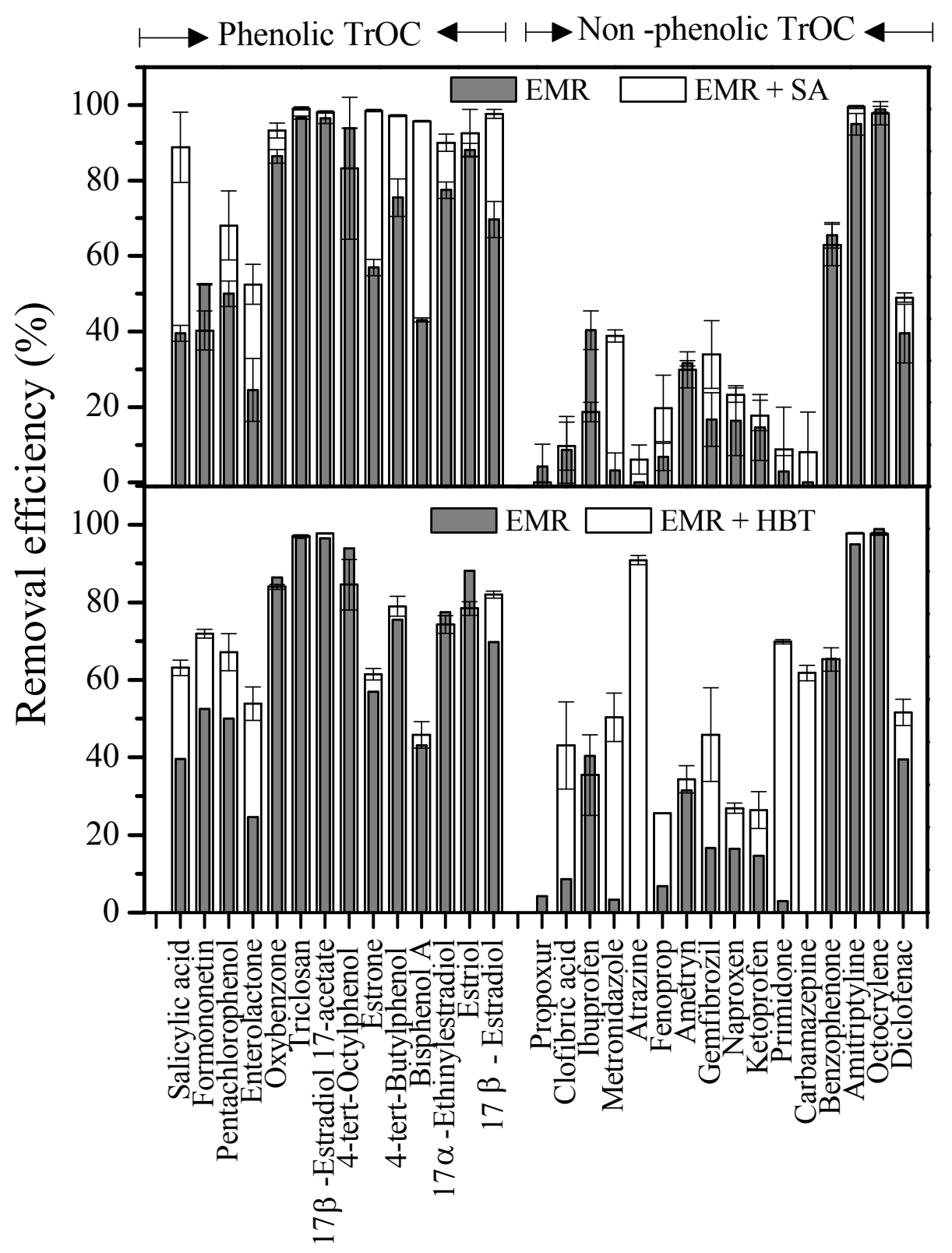

Figure 4 


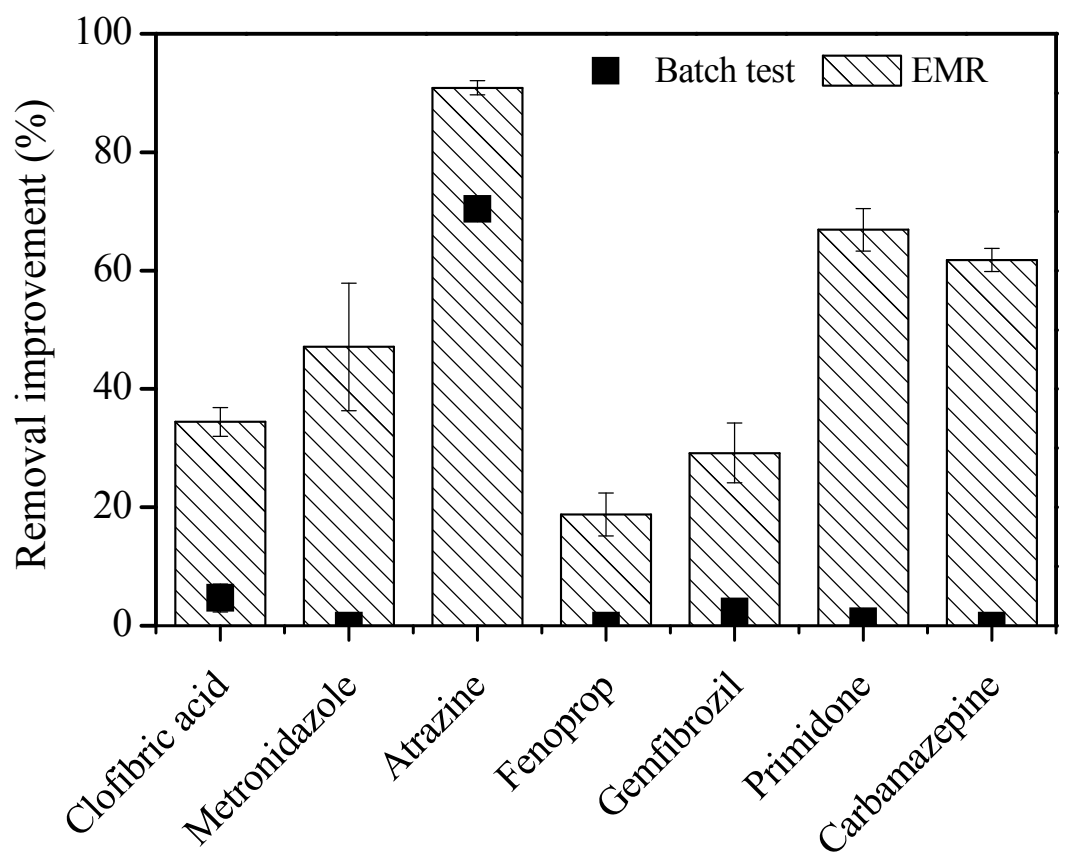

Figure 5 


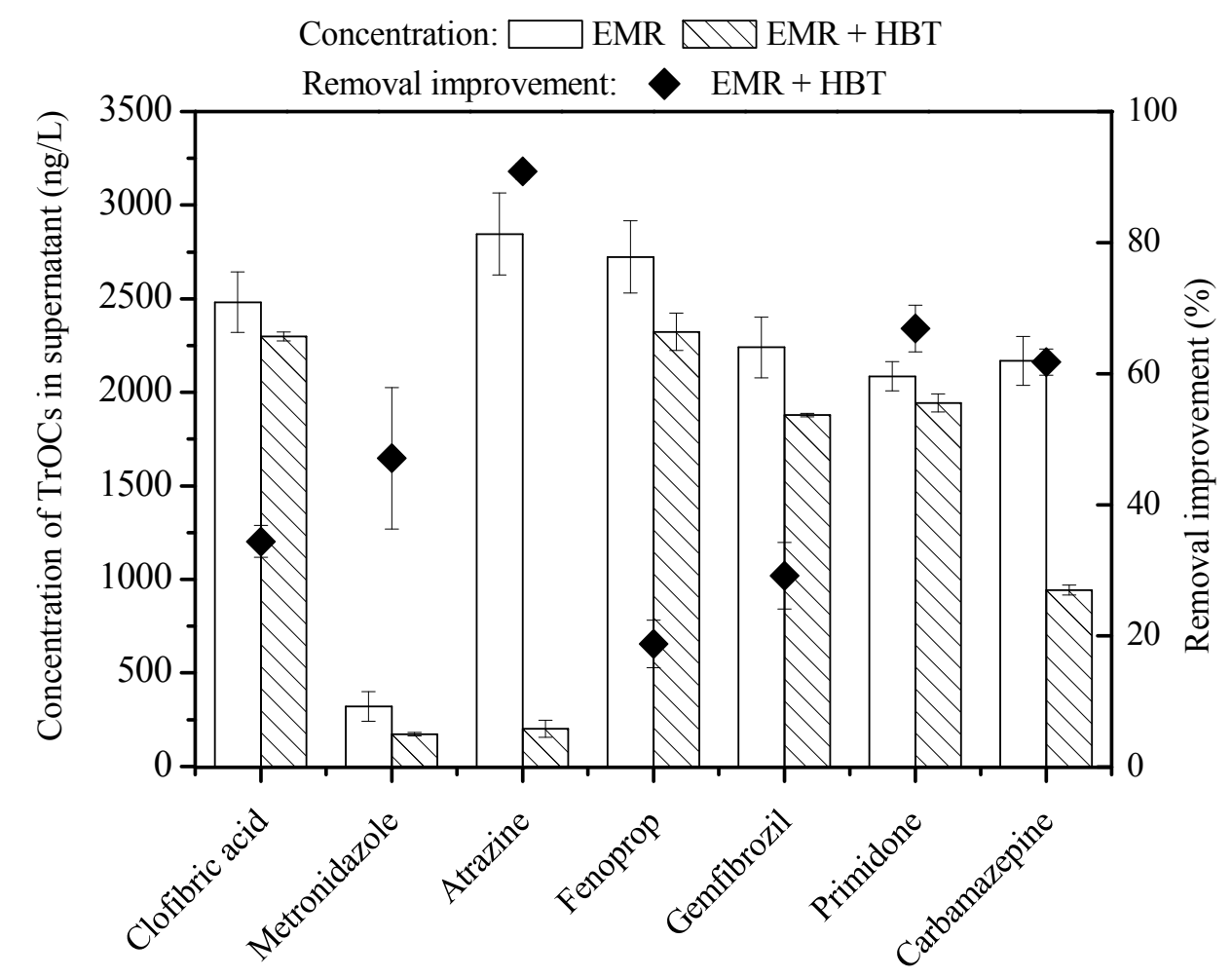

Figure 6 
Table 1: Assessment of TrOC degradation capacity of the laccase in batch tests. Values listed indicate average \pm standard deviation $(n=3)$.

\begin{tabular}{|c|c|c|c|}
\hline Category & Compound & $\begin{array}{c}\text { Phenolic } \\
\text { moiety }\end{array}$ & Enzymatic removal (\%) \\
\hline \multirow{10}{*}{ Pharmaceuticals } & Salicylic acid & Yes & 0 \\
\hline & Ibuprofen & & 0 \\
\hline & Metronidazole & & 0 \\
\hline & Naproxen & & 0 \\
\hline & Primidone & & $1.2 \pm 0.9$ \\
\hline & Amitriptyline & & $8.5 \pm 8.0$ \\
\hline & Carbamazepine & & $2.8 \pm 3.9$ \\
\hline & Ketoprofen & & 0 \\
\hline & Gemfibrozil & & 0 \\
\hline & Diclofenac & & $41.5 \pm 1.7$ \\
\hline \multirow{4}{*}{$\begin{array}{l}\text { Personal care } \\
\text { products }\end{array}$} & Triclosan & Yes & $88.7 \pm 3.9$ \\
\hline & Benzophenone & & $11.7 \pm 8.2$ \\
\hline & Oxybenzone & Yes & $6.1 \pm 8.5$ \\
\hline & Octocrylene & & $31.6 \pm 3.2$ \\
\hline \multirow{6}{*}{ Pesticides } & Propoxur & & 0 \\
\hline & Fenoprop & & 0 \\
\hline & Clofibric acid & & 0 \\
\hline & Atrazine & & 0 \\
\hline & Ametryn & & 0 \\
\hline & Pentachlorophenol & Yes & 0 \\
\hline \multirow{3}{*}{$\begin{array}{l}\text { Industrial } \\
\text { chemicals }\end{array}$} & 4-tert-Butylphenol & Yes & $95.5 \pm 2.5$ \\
\hline & Bisphenol A & Yes & $97.0 \pm 4.2$ \\
\hline & 4-tert-Octolphenol & Yes & $93.3 \pm 6.6$ \\
\hline \multirow{5}{*}{$\begin{array}{c}\text { Steroid } \\
\text { hormones }\end{array}$} & Estriol & Yes & $98.5 \pm 0.5$ \\
\hline & Estrone & Yes & $94.8 \pm 3.1$ \\
\hline & $17 \alpha$-Ethinylestradiol & Yes & $98.2 \pm 0.3$ \\
\hline & $17 \beta$-Estradiol & Yes & $98.5 \pm 0.1$ \\
\hline & $17 \beta$-Estradiol-17-acetate & Yes & $93.0 \pm 2.5$ \\
\hline \multirow{2}{*}{ Phytoestrogens } & Enterolactone & Yes & $4.2 \pm 5.8$ \\
\hline & Formononetin & Yes & 0 \\
\hline
\end{tabular}


Degradation of a broad spectrum of trace organic contaminants by an enzymatic membrane reactor: Complementary role of membrane retention and enzymatic degradation

\section{International Biodeterioration \& Biodegradation Vol 99, 20155 pp: 115-122 http://www.sciencedirect.com/science/article/pii/S0964830514003631}

Luong N. Nguyen ${ }^{a}$, Faisal I. Hai ${ }^{\text {a*}}$, William E. Price ${ }^{\mathrm{b}}$, Jinguo Kang ${ }^{\mathrm{b}}$, Frederic D.L. Leusch

${ }^{\mathrm{c}}$, Felicity Roddick ${ }^{\mathrm{d}}$, Jason P. van de Merwe ${ }^{\mathrm{c}}$, Saleh F. Magram ${ }^{\mathrm{e}}$, Long D. Nghiem ${ }^{\mathrm{a}}$

${ }^{a}$ Strategic Water Infrastructure Lab, School of Civil, Mining and Environmental Engineering, University of Wollongong, Wollongong, NSW 2522, Australia.

${ }^{\mathrm{b}}$ Strategic Water Infrastructure Lab, School of Chemistry, University of Wollongong, Wollongong, NSW 2522, Australia.

${ }^{\mathrm{c}}$ Smart Water Research Centre, Griffith University, QLD 4222, Australia

${ }^{\mathrm{d}}$ School of Civil, Environmental and Chemical Engineering, RMIT University, Melbourne, Victoria 3001, Australia

${ }^{\mathrm{e}}$ Department of Civil Engineering, King Abdul Aziz University, Jeddah 21589, Saudi Arabia

*Corresponding author: Faisal I. Hai, E-mail: faisal@uow.edu.au, Ph: + 61242213054 
Table S1: Physicochemical properties of the selected trace organic contaminants (TrOC)

\begin{tabular}{|c|c|c|c|c|c|c|c|}
\hline Category & $\begin{array}{l}\text { Compound } \\
\text { (CAS number) }\end{array}$ & $\begin{array}{l}\text { Molecular } \\
\text { weight } \\
\left(\mathrm{g} \mathrm{mol}^{-1}\right)\end{array}$ & $\begin{array}{c}\mathrm{Log} \\
\mathrm{K}_{\mathrm{OW}}{ }^{a}\end{array}$ & $\begin{array}{l}\log D \\
(\mathrm{pH} 7)^{\mathrm{a}}\end{array}$ & $\begin{array}{l}\text { Dissociati } \\
\text { on } \\
\text { constant } \\
(\mathrm{pKa})^{\mathrm{a}}\end{array}$ & $\begin{array}{l}\text { Limit of } \\
\text { detection } \\
(\mathrm{ng} / \mathrm{L})^{\mathrm{b}}\end{array}$ & Chemical structure \\
\hline \multirow{8}{*}{ 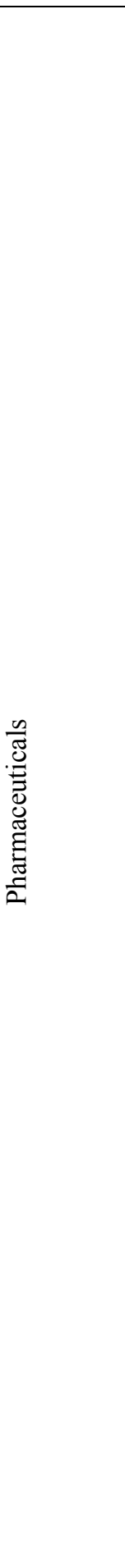 } & $\begin{array}{l}\text { Ibuprofen } \\
\left(\mathrm{C}_{13} \mathrm{H}_{18} \mathrm{O}_{2}\right) \\
(5687-27-1)\end{array}$ & 206.28 & $\begin{array}{c}3.50 \pm \\
0.23\end{array}$ & 0.94 & $\begin{array}{c}4.41 \pm \\
0.10\end{array}$ & 20 & \\
\hline & $\begin{array}{c}\text { Naproxen } \\
\left(\mathrm{C}_{14} \mathrm{H}_{14} \mathrm{O}_{3}\right) \\
(22204-53-1)\end{array}$ & 230.26 & $\begin{array}{c}2.88 \pm \\
0.24\end{array}$ & 0.73 & $\begin{array}{c}4.84 \pm \\
0.30\end{array}$ & 1 & \\
\hline & $\begin{array}{l}\text { Ketoprofen } \\
\left(\mathrm{C}_{16} \mathrm{H}_{14} \mathrm{O}_{3}\right) \\
(22071-15-4)\end{array}$ & 254.28 & $\begin{array}{c}2.91 \pm \\
0.33\end{array}$ & 0.19 & $\begin{array}{c}4.23 \pm \\
0.10\end{array}$ & 20 & \\
\hline & $\begin{array}{c}\text { Diclofenac } \\
\left(\mathrm{C}_{14} \mathrm{H}_{11} \mathrm{Cl}_{2} \mathrm{NO}_{2}\right) \\
(15307-86-5)\end{array}$ & 296.15 & $\begin{array}{c}4.55 \pm \\
0.57\end{array}$ & 1.77 & $\begin{array}{c}4.18 \pm \\
0.10 \\
\\
-2.26 \pm \\
0.50\end{array}$ & 5 & \\
\hline & $\begin{array}{c}\text { Primidone } \\
\left(\mathrm{C}_{12} \mathrm{H}_{14} \mathrm{~N}_{2} \mathrm{O}_{2}\right) \\
(125-33-7)\end{array}$ & 218.25 & $\begin{array}{c}0.83 \pm \\
0.50\end{array}$ & 0.83 & $\begin{array}{c}12.26 \pm \\
0.40 \\
\\
-1.07 \pm \\
0.40\end{array}$ & 10 & \\
\hline & $\begin{array}{c}\text { Carbamazepine } \\
\left(\mathrm{C}_{15} \mathrm{H}_{12} \mathrm{~N}_{2} \mathrm{O}\right) \\
(298-46-4)\end{array}$ & 236.27 & $\begin{array}{c}1.89 \pm \\
0.59\end{array}$ & 1.89 & $\begin{array}{c}13.94 \pm \\
0.20 \\
\\
-0.49 \pm \\
0.20\end{array}$ & 10 & \\
\hline & $\begin{array}{c}\text { Salicylic acid } \\
\left(\mathrm{C}_{7} \mathrm{H}_{6} \mathrm{O}_{3}\right) \\
(69-72-7)\end{array}$ & 138.12 & $\begin{array}{c}2.01 \pm \\
0.25\end{array}$ & -1.13 & $\begin{array}{c}3.01 \pm \\
0.10\end{array}$ & 1 & \\
\hline & $\begin{array}{c}\text { Metronidazole } \\
\left(\mathrm{C}_{6} \mathrm{H}_{9} \mathrm{~N}_{3} \mathrm{O}_{3}\right) \\
(443-48-1)\end{array}$ & 171.15 & $\begin{array}{c}-0.14 \pm \\
0.30\end{array}$ & -0.14 & $\begin{array}{c}14.44 \pm \\
0.10 \\
\\
2.58 \pm \\
0.34\end{array}$ & 20 & \\
\hline
\end{tabular}




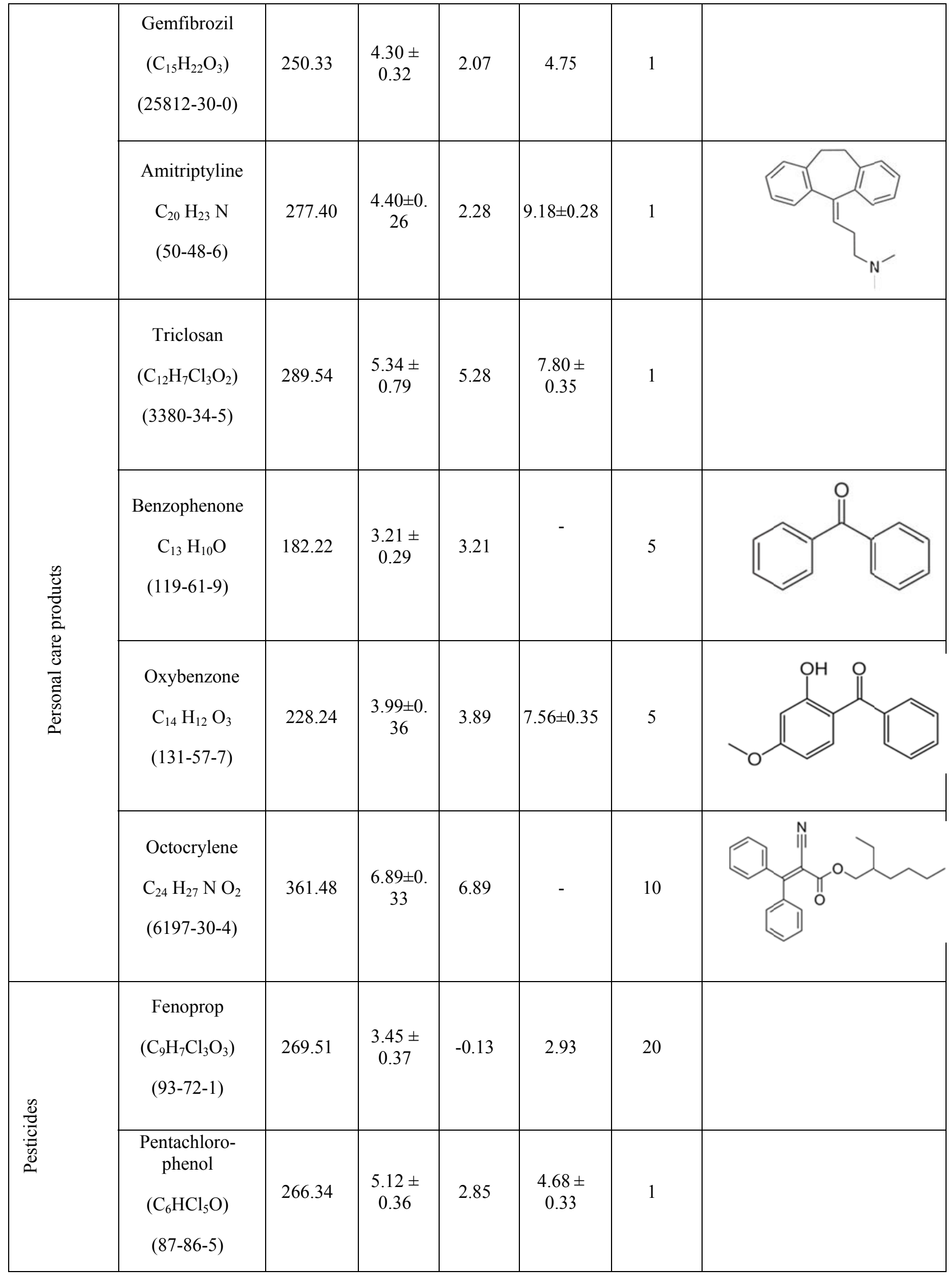




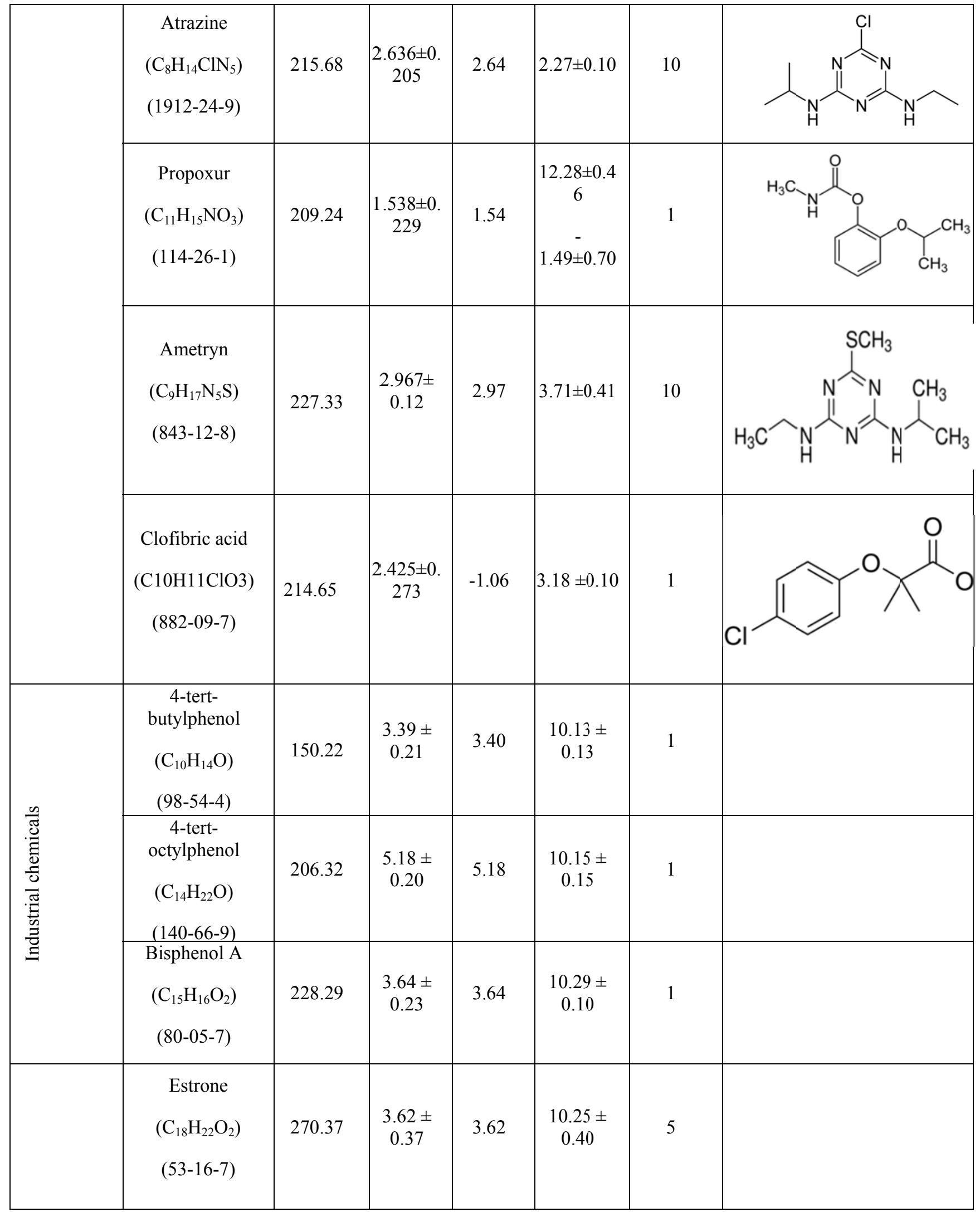




\begin{tabular}{|c|c|c|c|c|c|c|c|}
\hline \multirow{4}{*}{ 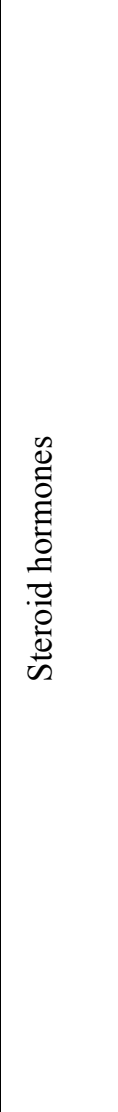 } & $\begin{array}{c}\text { 17ß-estradiol } \\
\left(\mathrm{C}_{18} \mathrm{H}_{24} \mathrm{O}_{2}\right) \\
(50-28-2)\end{array}$ & 272.38 & $\begin{array}{c}4.15 \pm \\
0.26\end{array}$ & 4.15 & 10.27 & 5 & \\
\hline & $\begin{array}{c}\text { 17 } \beta \text {-estradiol } 17- \\
\text { acetate } \\
\left(\mathrm{C}_{20} \mathrm{H}_{26} \mathrm{O}_{3}\right) \\
(1743-60-8)\end{array}$ & 314.42 & $\begin{array}{c}5.11 \pm \\
0.28\end{array}$ & 5.11 & $\begin{array}{c}10.26 \pm \\
0.60\end{array}$ & 5 & \\
\hline & $\begin{array}{c}\left(\mathrm{C}_{20} \mathrm{H}_{24} \mathrm{O}_{2}\right) \\
(57-63-6)\end{array}$ & 269.40 & $\begin{array}{c}4.10 \pm \\
0.31\end{array}$ & 4.11 & $\begin{array}{c}10.24 \pm \\
0.60\end{array}$ & 10 & \\
\hline & $\begin{array}{c}\text { Estriol (E3) } \\
\left(\mathrm{C}_{18} \mathrm{H}_{24} \mathrm{O}_{3}\right) \\
(50-27-1)\end{array}$ & 288.38 & $\begin{array}{c}2.53 \pm \\
0.28\end{array}$ & 2.53 & $\begin{array}{c}10.25 \pm \\
0.70\end{array}$ & 10 & \\
\hline \multirow[b]{2}{*}{ 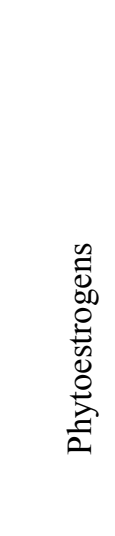 } & $\begin{array}{l}\text { Formononetin } \\
\qquad \mathrm{C}_{16} \mathrm{H}_{12} \mathrm{O}_{4} \\
(485-72-3)\end{array}$ & 268.26 & $\begin{array}{c}2.86 \\
\pm 1.13\end{array}$ & 2.55 & $6.99 \pm 0.20$ & 10 & 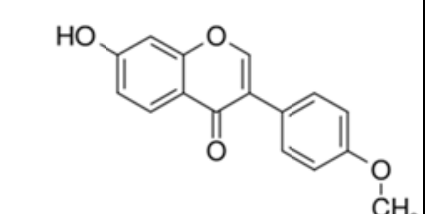 \\
\hline & $\begin{array}{l}\text { Enterolactone } \\
\mathrm{C}_{18} \mathrm{H}_{18} \mathrm{O}_{4} \\
(78473-71-9)\end{array}$ & 298.33 & $\begin{array}{c}1.89 \pm \\
0.37\end{array}$ & 1.89 & $9.93 \pm 0.10$ & 10 & \\
\hline
\end{tabular}

${ }^{a}$ Source: SciFinder database https://scifinder.cas.org/scifinder/view/scifinder/scifinderExplore.jsf $\log D$ is $\operatorname{logarithm}$ of the distribution coefficient which is the ratio of the sum of concentrations of all forms of the compound (ionised and unionised) in octanol and water at a given $\mathrm{pH}$. 


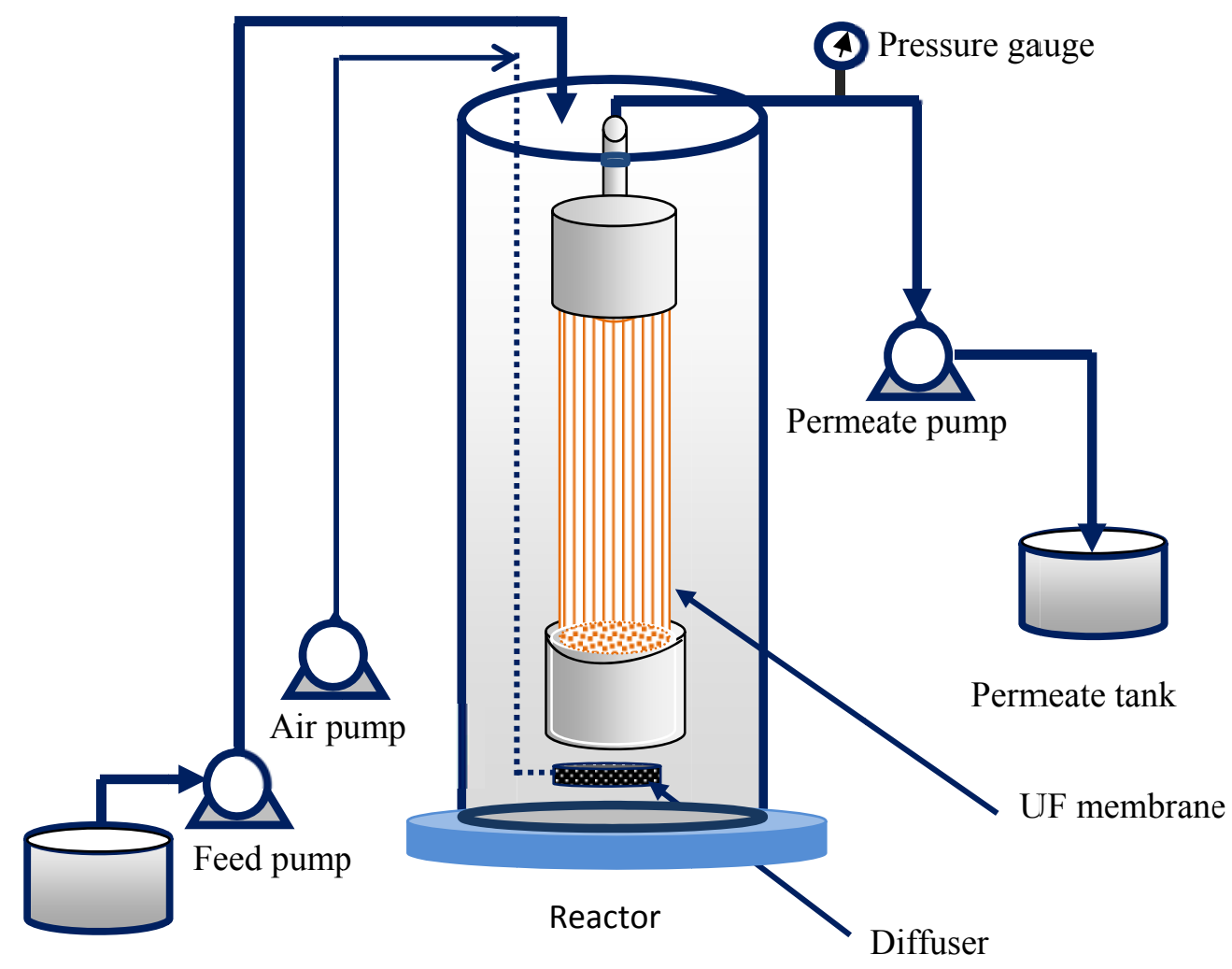

Feed tank

Figure S2: Schematic diagram of the enzymatic membrane reactor 
Table S3: Gradient eluent profiles used in HPLC-UV analyses

The column temperature was set at $20^{\circ} \mathrm{C}$. A sample injection volume of $50 \mu \mathrm{L}$ was used. The mobile phase composed of acetonitrile and Milli-Q grade deionized water buffered with $25 \mathrm{mM} \mathrm{KH}_{2} \mathrm{PO}_{4}$. Two eluents, namely, eluent $\mathbf{A}(80 \%$ acetonitrile $+20 \%$ buffer, $\mathrm{v} / \mathrm{v})$ and eluent B (20\% acetonitrile $+80 \%$ buffer, $\mathrm{v} / \mathrm{v})$ were delivered at $0.7 \mathrm{~mL} / \mathrm{min}$ through the column. The detection wavelength was set at $280 \mathrm{~nm}$ for pentachlorophenol, oxybenzone and benzophenone and at $225 \mathrm{~nm}$ for ketoprofen.

For pentachlorophenol, oxybenzone and benzophenone

\begin{tabular}{|l|c|c|c|c|c|c|c|c|}
\hline Time (min) & 0 & 12 & 20 & 25 & 25 & & & \\
\hline Eluent B, \% & 85 & 80 & 0 & 0 & 80 & & & \\
\hline \multicolumn{7}{|c|}{ For ketoprofen } \\
\hline Time (min) & 0 & 7 & 19 & 20 & 35 & & & \\
\hline Eluent B, \% & 50 & 50 & 20 & 50 & 50 & & & \\
\hline
\end{tabular}


Table S4: Statistical analysis of data

\begin{tabular}{|c|c|c|c|c|c|}
\hline & & \multicolumn{4}{|c|}{$p$ value } \\
\hline Category & Compounds & $\begin{array}{l}\text { 'Laccase- } \\
\text { EMR' versus } \\
\text { 'Laccase- } \\
\text { Batch test' } \\
\text { (Figure 1) }\end{array}$ & $\begin{array}{c}\text { Laccase-EMR } \\
\text { versus } \\
\text { 'Laccase- } \\
\text { EMR-HBT' } \\
\text { (Figure 4) }\end{array}$ & $\begin{array}{l}\text { 'Laccase- } \\
\text { EMR' versus } \\
\text { 'Laccase- } \\
\text { EMR-SA' } \\
\text { (Figure 4) }\end{array}$ & $\begin{array}{c}\text { 'Laccase-EMR- } \\
\text { HBT' versus } \\
\text { 'Laccase-EMR- } \\
\text { SA' } \\
\text { (Figure 4) }\end{array}$ \\
\hline \multirow{14}{*}{ 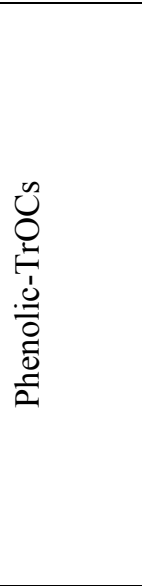 } & Salicylic acid & 0.004 & 0.009 & 0.012 & 0.031 \\
\hline & Formononetin & 0.008 & 0.033 & 0.236 & 0.003 \\
\hline & Pentachlorophenol & 0.001 & 0.004 & 0.477 & 0.07 \\
\hline & Enterolactone & 0.174 & 0.04 & 0.048 & 0.225 \\
\hline & Oxybenzone & 0.003 & 0.193 & 0.047 & 0.016 \\
\hline & Triclosan & 0.055 & 0.225 & 0.035 & 0.074 \\
\hline & $17 \beta$-Estradiol 17-acetate & 0.02 & 0.296 & 0.128 & 0.225 \\
\hline & 4-tert-Octylphenol & 0.904 & 0.073 & 0.318 & 0.912 \\
\hline & Estrone & 0.001 & 0.225 & 0.247 & 0.004 \\
\hline & 4-tert-Butylphenol & 0.022 & 0.38 & 0.009 & 0.003 \\
\hline & Bisphenol A & 0.002 & 0.443 & 0 & 0.001 \\
\hline & $17 \alpha$-Ethinylestradiol & 0.006 & 0.504 & 0.01 & 0.023 \\
\hline & Estriol & 0.004 & 0.02 & 0.28 & 0.019 \\
\hline & $17 \beta$ - Estradiol & 0.008 & 0.038 & 0.009 & 0 \\
\hline \multirow{17}{*}{ 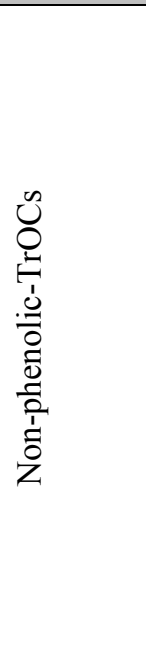 } & & & & & \\
\hline & Propoxur & 0.267 & 0.267 & 0.267 & 0.267 \\
\hline & Clofibric acid & 0.138 & 0.001 & 0.87 & 0.046 \\
\hline & Ibuprofen & 0.002 & 0.743 & 0.283 & 0.089 \\
\hline & Metronidazole & 0.423 & 0.01 & 0.002 & 0.073 \\
\hline & Atrazine & - & 0 & 0.06 & 0 \\
\hline & Fenoprop & 0.233 & 0.015 & 0.106 & 0.249 \\
\hline & Ametryn & 0 & 0.317 & 0.734 & 0.248 \\
\hline & Gemfibrozil & 0.044 & 0.007 & 0.115 & 0.296 \\
\hline & Naproxen & 0.05 & 0.082 & 0.302 & 0.147 \\
\hline & Ketoprofen & 0.252 & 0.152 & 0.374 & 0 \\
\hline & Primidone & 0.561 & 0.001 & 0.398 & 0.006 \\
\hline & Carbamazepine & 0.238 & 0 & 0.207 & 0.004 \\
\hline & Benzophenone & 0.003 & 0.829 & 0.043 & 0.49 \\
\hline & Amitriptyline & 0.003 & 0.124 & 0.094 & 0 \\
\hline & Octocrylene & 0 & 0.057 & 0.478 & 0.84 \\
\hline & Diclofenac & 0.701 & 0.02 & 0.115 & 0.271 \\
\hline
\end{tabular}




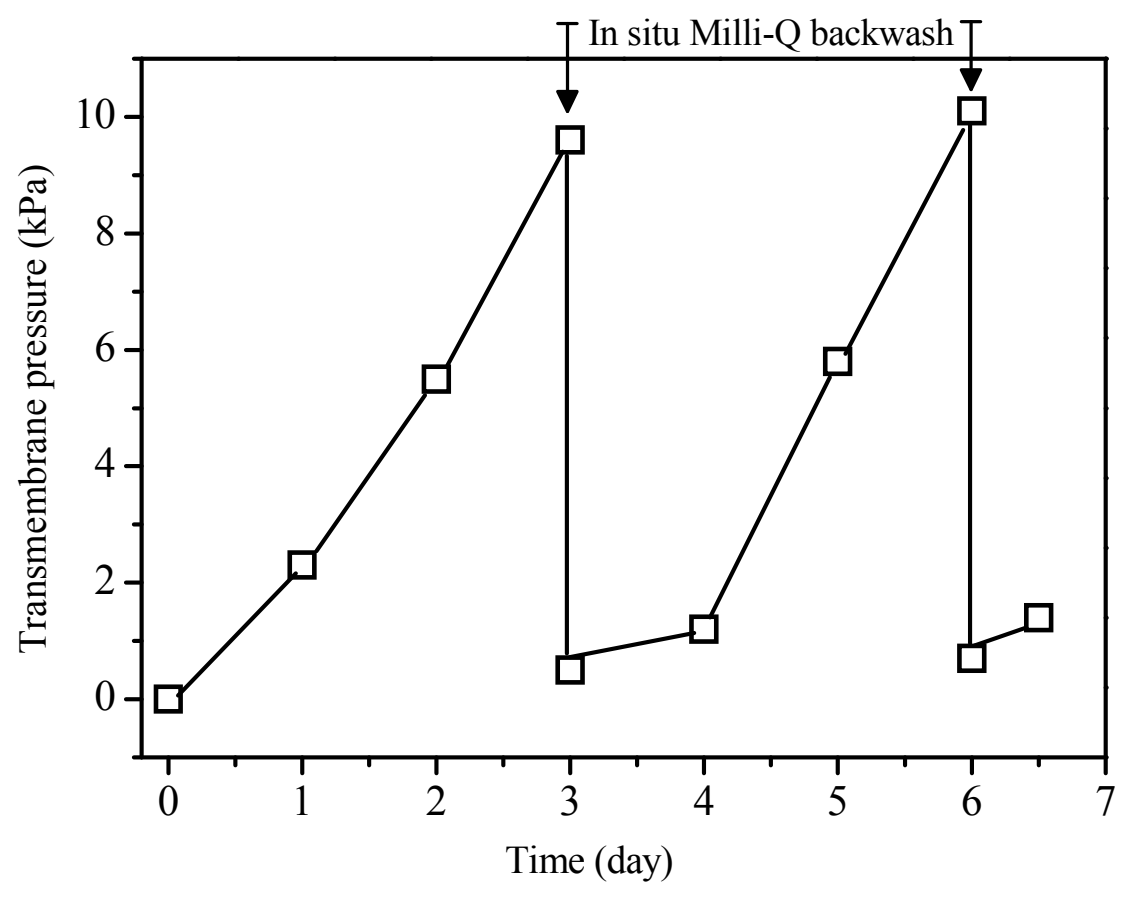

Figure S5: Transmembrane pressure (TMP) during continuous operation of the EMR. The membrane was cleaned by in situ Milli-Q backwash at a flux of $24 \mathrm{~L} / \mathrm{m}^{2} \mathrm{~h}$ for $5 \mathrm{~s}$ (thus introducing 6.5 mL Milli-Q water per backwash) when the TMP exceeded $10 \mathrm{kPa}$. 


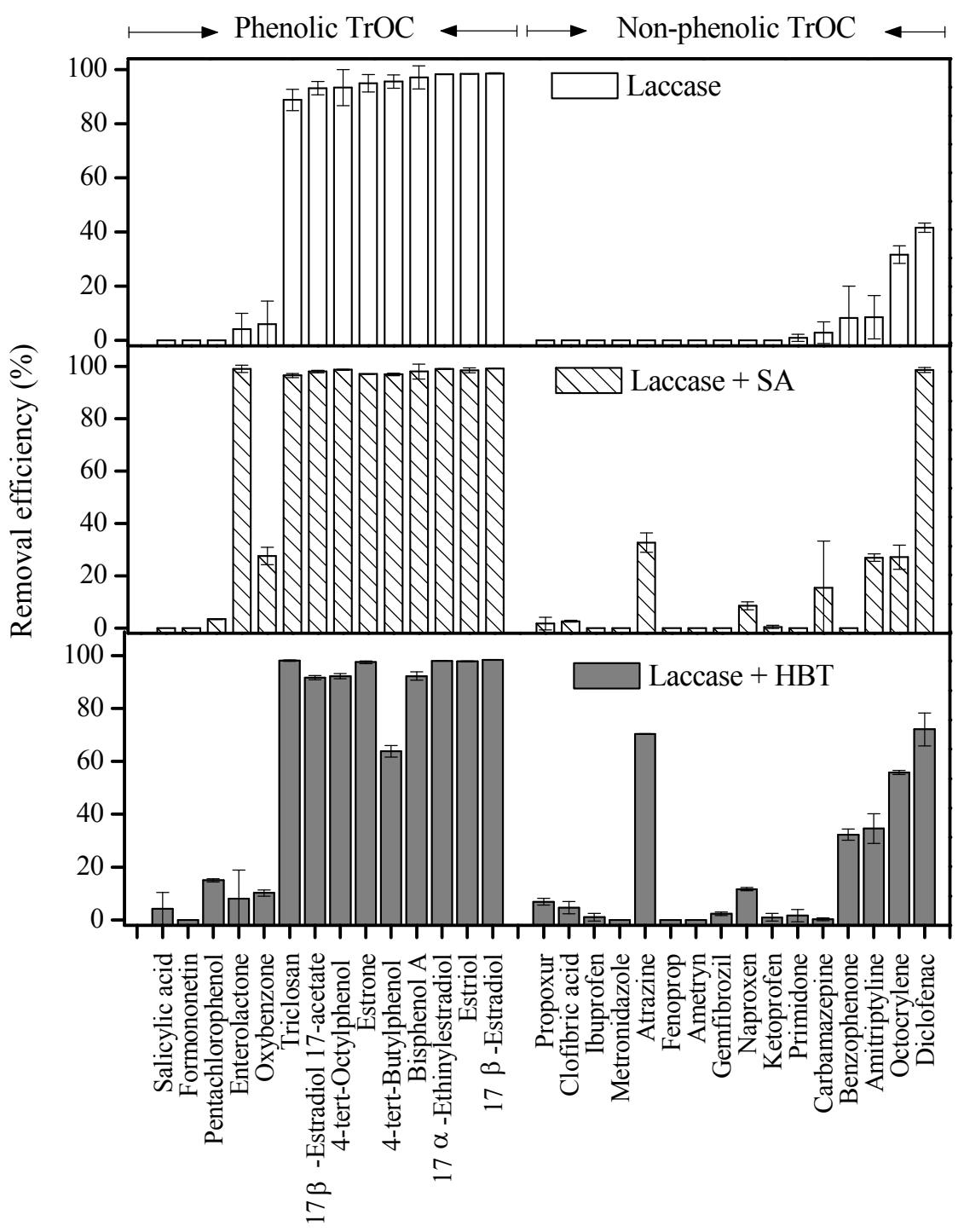

Figure S6: Laccase-catalysed degradation of $30 \mathrm{TrOCs}$ during batch tests in presence of the mediators (SA or HBT) at a concentration of $10 \mu \mathrm{M}$. The error bars represent the standard deviation of three replicates. 